Article

\title{
Investigations for a Trajectory Variation to Improve the Energy Conversion for a Four-Stroke Free-Piston Engine
}

\author{
Robin Tempelhagen ${ }^{1, *}$, Andreas Gerlach ${ }^{2}{ }^{\oplus}$, Sebastian Benecke ${ }^{2}{ }^{\oplus}$, Kevin Klepatz $^{1}$, Roberto Leidhold ${ }^{2}(\mathbb{D}$ and \\ Hermann Rottengruber ${ }^{1}$ \\ 1 Department of Mobile Systems, Otto-von-Guericke University, 39016 Magdeburg, Germany; \\ kevin.klepatz@ovgu.de (K.K.); hermann.rottengruber@ovgu.de (H.R.) \\ 2 Department of Electric Power Systems, Otto-von-Guericke University, 39016 Magdeburg, Germany; \\ andreas.gerlach@ovgu.de (A.G.); sebastian.benecke@ovgu.de (S.B.); roberto.leidhold@ovgu.de (R.L.) \\ * Correspondence: robin.tempelhagen@ovgu.de; Tel.: +49-391-67-52307
}

check for updates

Citation: Tempelhagen, R.; Gerlach, A.; Benecke, S.; Klepatz, K.; Leidhold, R.; Rottengruber, H. Investigations for a Trajectory Variation to Improve the Energy Conversion for a Four-Stroke Free-Piston Engine. Appl. Sci. 2021, 11, 5981. https://doi.org/10.3390/ app11135981

Academic Editors: Cinzia Tornatore and Luca Marchitto

Received: 31 May 2021

Accepted: 24 June 2021

Published: 27 June 2021

Publisher's Note: MDPI stays neutra with regard to jurisdictional claims in published maps and institutional affiliations.

Copyright: (c) 2021 by the authors. Licensee MDPI, Basel, Switzerland. This article is an open access article distributed under the terms and conditions of the Creative Commons Attribution (CC BY) license (https:// creativecommons.org/licenses/by/ $4.0 /)$.
Featured Application: This work deals with the influence of the trajectory variation on the combustion process. The stroke trajectory is varied for a constant period and the losses that occur in the internal combustion engine and the electrical machine are examined. The developed methods were used for a four-stroke free-piston engine.

Abstract: Internal combustion engines with a crankshaft have been successfully developed for many years. They are lacking in the fact that the piston trajectory, i.e., position as a function of time, is limited by the crankshaft motion law. Position-controlled electric linear machines directly coupled to the piston allow to realize free-piston engines. Unlike the crankshaft-based engines, they allow for a higher degree of freedom in shaping the piston trajectory, including adaptive compression ratios, which enables optimal operation with alternative fuels. The possibility of adapting the stroke course results in new degrees of freedom with which the combustion process can be optimized. In this work, four-stroke trajectories with different amplitudes and piston dynamics have been proposed and analyzed regarding efficiency. A simulation model was created based on experimental measurements for testing the proposed trajectories. It could be proved that the variation of the trajectory resulted in an improvement of the overall efficiency. The trajectories were described analytically so that they can be used for a prototype in a future work.

Keywords: free-piston engine; linear permanent magnet synchronous machine; four-stroke; energyconversion; efficiency improvement

\section{Introduction}

The internal combustion engine is one of the most common engines. With this motor, chemically stored energy is converted into mechanical energy. The energy conversion unfortunately produces exhaust gases and losses, which is the focus of research of many scientific elaborations [1]. To improve efficiency [2,3], various components were optimized [4], control strategies were adapted, valve timing was varied [5], alternative fuels [6] were investigated and much more.

Due to the shortage of fossil resources and the environmental impact of the combustion engine, alternative concepts for optimal energy conversion are being investigated. One possible future-oriented concept here is the free-piston engine [7-9]. The free-piston engine consists of an internal combustion engine, where the piston is connected to a linear electrical machine [10-12]. This means that no crankshaft is required, which makes it possible to vary the stroke trajectory, and thus, also the compression ratio. Various prototypes have already been developed $[13,14]$. With these prototypes, it could be shown that the operation of a two- or four-stroke free-piston engine is possible [15-17]. 
The free piston engine offers different research focuses. One major focus is the optimization of the control strategy [16,18-21]. Another focus is the analyzation of the combustion process [22-24]. As a third major research focus, the modeling investigation of the modeling of a free-piston engine can be defined $[25,26]$. The fourth research topic is the optimal design of electric machines [27-29].

In addition to varying the compression ratio, it is also possible to adjust the stroke trajectory if the linear machine is adequately controlled [8]. The influence of the piston trajectory on the combustion is also a very interesting research topic [30,31]. In the present work, different stroke trajectories are proposed and analyzed with respect to the losses in the combustion process and conversion of mechanical energy to electric energy with an electric machine. The novelty of this work is the analyzation of the system efficiency of a free-piston engine with respect to the piston trajectory. There was particular interest in how the losses can be varied with a variation in the stroke amplitude, the acceleration of the piston and a time shift based on the TDCF. It could be proved that the stroke course has a major influence on the efficiency of the internal combustion engine. In Section 2, it is explained how the chemically stored energy is converted into electrical energy. Section 3 explains how the experimental prototype is constructed. For the prototype, a thermodynamic model and an electromechanical model were designed, which are described in Sections 4 and 5, respectively. With these models, it is possible to determine the energy conversion losses. The same piston stroke curves were specified for the models. The generation of trajectories is explained in Section 6. The results are presented in Section 7 and summarized in Section 8.

\section{Consideration of the Energy Losses for Converting Chemically Stored Energy into Electrical Energy}

To justify the pros and cons for different piston trajectories regarding the thermodynamic and electric efficiency of the free-piston engine, a loss analysis is used. Depending on the piston trajectory, different losses may result in terms of combustion characteristics, heat losses, gas exchange, compression and expansion characteristics.

The chemical fuel energy $E_{f u e l}$, which enters the engine via the injector, represents the maximal supplied energy for the engine and is the basis of the loss analysis. This energy only depends on the injected mass $m_{f u e l}$ and the lower heat value $L H V$ according to:

$$
E_{f u e l}=m_{f u e l} \cdot L H V .
$$

This chemical energy is transformed to thermal energy during the combustion process. Due to the fact that an ideal combustion is not realizable, there is always an amount of unburned fuel $m_{u n b}$, which leads to an energy loss during the transformation from chemical to thermal energy $E_{t h}$. Besides the imperfect combustion, incomplete combustion could occur when injected fuel is not completely thermally converted and oxidized. When fuel reaches the cylinder wall or the upper face of the piston during combustion, the flame extinguishes and is, thus, not available for further thermal conversion. Out of the difference of the incomplete converted fuel and the injected fuel, incomplete combustion efficiency can be derived. The parameter $\eta_{c o m b}$ describes the efficiency of the combustion based on the converted fuel mass, whereby the thermal energy yields to:

$$
E_{t h}=\left(m_{f u e l}-m_{u n b}\right) \cdot L H V=\eta_{c o m b} \cdot E_{f u e l} .
$$

This thermal energy is the basis for the volume change work. Due to the fact that an energy loss analysis is used for the comparison, the volume change work is called here the volume change energy $E_{v c}$. The combustion process creates high temperature gradients, which lead to an energy loss through the walls $E_{w a l}$. This is described by the heat flux through the walls of the combustion chamber, which is defined by:

$$
E_{\text {wal }}=\alpha \cdot A \cdot \Delta T \cdot \Delta t .
$$


where $\alpha$ is the heat transfer coefficient (HTC), $A$ is the area of the combustion chamber, $\Delta T$ is the temperature gradient between the surrounding solid material and the gas inside the combustion chamber and $\Delta t$ is the time in which the process is performed. All parameters are space- and time-dependent. The parameters in Equation (3) are mean values over one work cycle to simplify the formulas for a better understanding [32]. The time-dependent temperature at the wall, which is causing $\Delta T$, is influenced by all three ways of heat transfer. Due to the very low thermal conductivity coefficient of air, the influence of the conduction within the combustion chamber is low as well. The influence of the radiation to the wall temperature depends on the used ignition strategy and the corresponding injection system. Diesel engines with direct injection are more influenced as gasoline engines in general and especially with port fuel injection. The last influence is the convection. Due to the fast motion of the gas mixture inside the combustion chamber, it has strongest influence.

Not all of the thermal energy can be transformed into volume change energy within the given time for the expansion stroke. Therefore, thermal energy $E_{\text {exh }}$ is lost within the exhaust gas when leaving the combustion chamber over the exhaust valve, as defined as:

$$
E_{\text {exh }}=E_{\text {int out }}-E_{\text {int in }}=\left(T_{\text {out }} \cdot c_{p_{\text {out }}}-T_{\text {in }} \cdot c_{p_{\text {in }}}\right) \cdot m_{\text {gas }} .
$$

where $E_{\text {int out }}$ is the internal energy within the exhaust gas, $E_{\text {int }}$ in is the internal energy within the supplied air-fuel-mixture, $\mathrm{T}$ is the mean temperature, $c_{p}$ is the mean specific heat capacity and $m_{g a s}$ is the gas mass which is supplied and exhausted. The values for $T$ and $c_{p}$ of the supplied and exhaust gas are averaged over the time during which the specific valve is open.

The volume change energy $E_{v c}$ is the balance of the thermal energy, the wall heat losses and the thermal energy losses through the exhaust. The losses can be described by the thermal efficiency $\eta_{t h}$. The volume change energy, thus, results in:

$$
E_{v c}=E_{t h}-E_{w a l}-E_{e x h}=\eta_{t h} \cdot E_{t h} .
$$

The volume change energy leads to a motion of the piston, which in turns is always subject to friction. The friction losses arise mainly in our prototype in the piston rings, bearings and the valve train. The mechanical energy $E_{M}$ is the subtraction of the friction energy from the volume change energy and can be described by the friction efficiency loss $\eta_{F r}$ as follows:

$$
E_{M}=E_{v c}-E_{F r}=\eta_{F r} \cdot E_{v c}
$$

As described in Equation (6), friction occurs, which can also be described as:

$$
P_{F r}=v^{2} \cdot u=F_{F r} \cdot v,
$$

where $\mu$ the coefficient of friction and $v$ is the speed of the translator.

The mechanical power $P_{M}$ for the electrical machine can be expressed as:

$$
P_{M}=F_{E M} \cdot v,
$$

where $F_{E M}$ is the force of the electric machine. Due to the oscillation of the translator, the system requires acceleration power $P_{a c c}$ in many operating points. The acceleration power can be expressed with:

$$
P_{a c c}=m \cdot \frac{d v}{d t} \cdot v,
$$

where $m$ is the accelerated mass of the system and $\frac{d v}{d t}$ the time derivative of the speed. The power output from the internal combustion engine $P_{I C E}$ can be described with:

$$
P_{I C E}=F_{p} \cdot v=A_{c y l} \cdot p \cdot v,
$$


where $p$ is the cylinder pressure, $A_{c y l}$ is the area of the piston and $F_{p}$ is the gas force. In addition, in the electrical machine the reluctance power $P_{R e l}$ arises, which can be described as a function of position:

$$
P_{\text {Rel }}=f(x) \cdot v .
$$

The power equilibrium on the mechanical transmission element results as follows:

$$
P_{I C E}+P_{M}+P_{F r}+P_{R e l}=P_{a c c} .
$$

In the case of a directly driven free-piston engine [17], the trajectory can be varied highly dynamically with the electric machine using the field oriented control. This is possible with the electrical machine force $F_{E M}$, which is proportional to the current $i_{q}$ via the force constant $k_{F}$. The force of the electric machine can be expressed with:

$$
F_{E M}=\frac{3}{2} k_{F} i_{q}
$$

The mechanical energy can be converted into electrical energy with the help of the electrical machine.

The special feature of the free-piston engine is that it does not have a crankshaft. The required oscillation movement of the piston can be realized with the help of a linear electric machine. The electrical machines can be constructed in different ways $[27,33,34]$. Depending on the machine type, different power losses can arise. The power loss occurs when the iron is re-magnetized, which is referred to as hysteresis power loss $P_{H y s}$. Eddy current power dissipation $P_{F t}$ can also arise. The sum of the hysteresis power loss and the eddy current power loss is referred to as the iron power loss $P_{F e}$ :

$$
P_{F e}=P_{F t}+P_{H y s} .
$$

In addition to the iron power loss, there is also a power loss due to the current $i_{q}$ in a coil winding with ohmic resistance $R$. This power loss is referred to as the copper power loss. The copper power losses are calculated in the $\mathrm{d} / \mathrm{q}$-reference frame as follows:

$$
P_{C u}=\frac{3}{2}\left(i_{q}^{2}+i_{d}^{2}\right) \cdot R
$$

Due to the iron and copper power losses, the entire mechanical power on the electrical machine cannot completely be converted into electrical power. This can be expressed stationary as follows:

$$
P_{M}+P_{C u}+P_{F e}=P_{e l} .
$$

The electrical power $P_{e l}$ can be determined with the voltages $u_{d, q}$ and currents $i_{d, q}$.

$$
P_{e l}=\frac{3}{2}\left(u_{d} \cdot i_{d}+u_{q} \cdot i_{q}\right)
$$

By integrating the calculated powers over a cycle, it is possible to calculate the energies.

\section{Experimental Prototype}

The experimental measurements for the validation of the simulation model were obtained with the help of the prototype in Figure 1 and is shown schematically in Figure 2. 


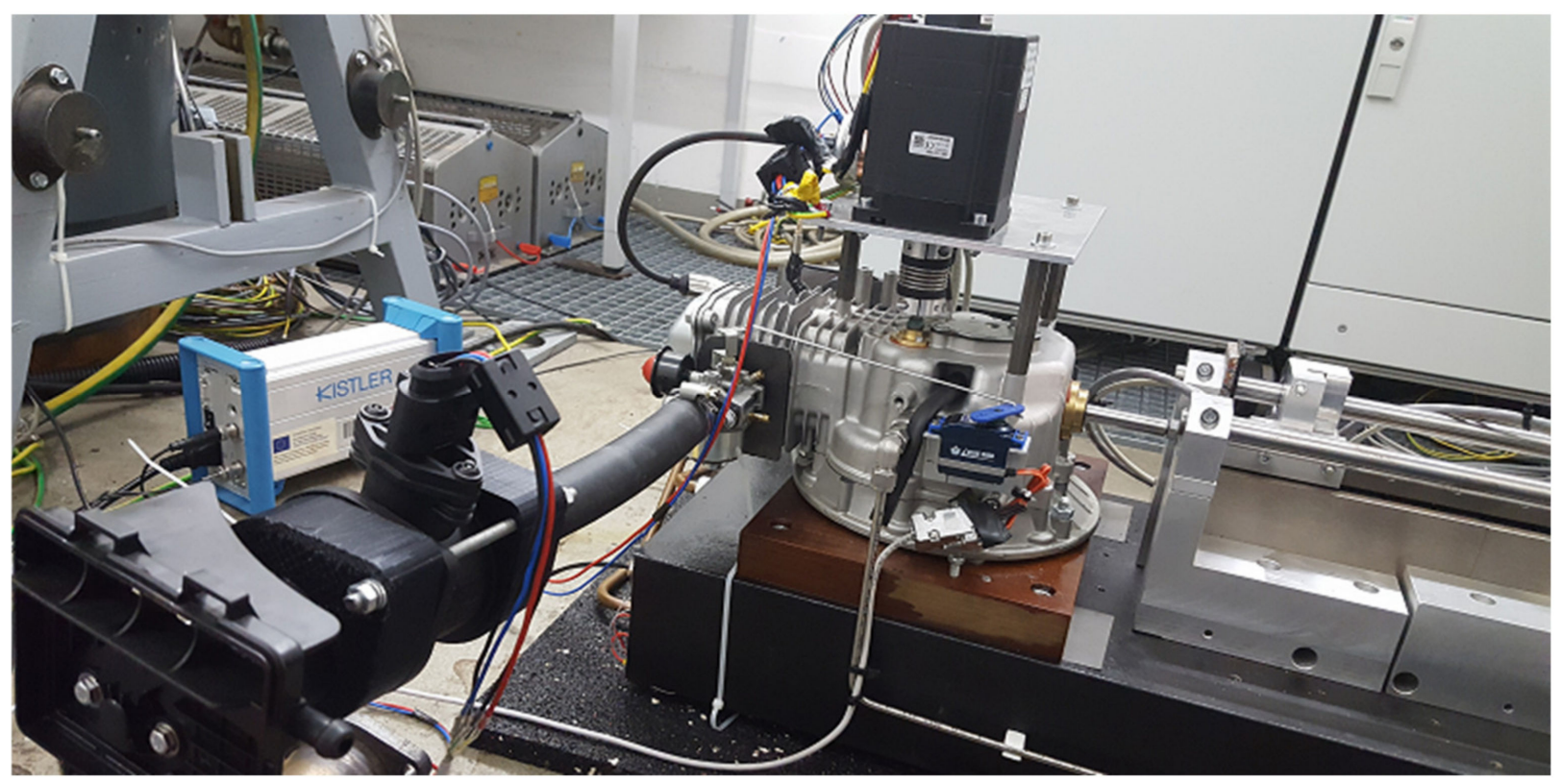

Figure 1. Experimental Prototype of the free-piston engine.

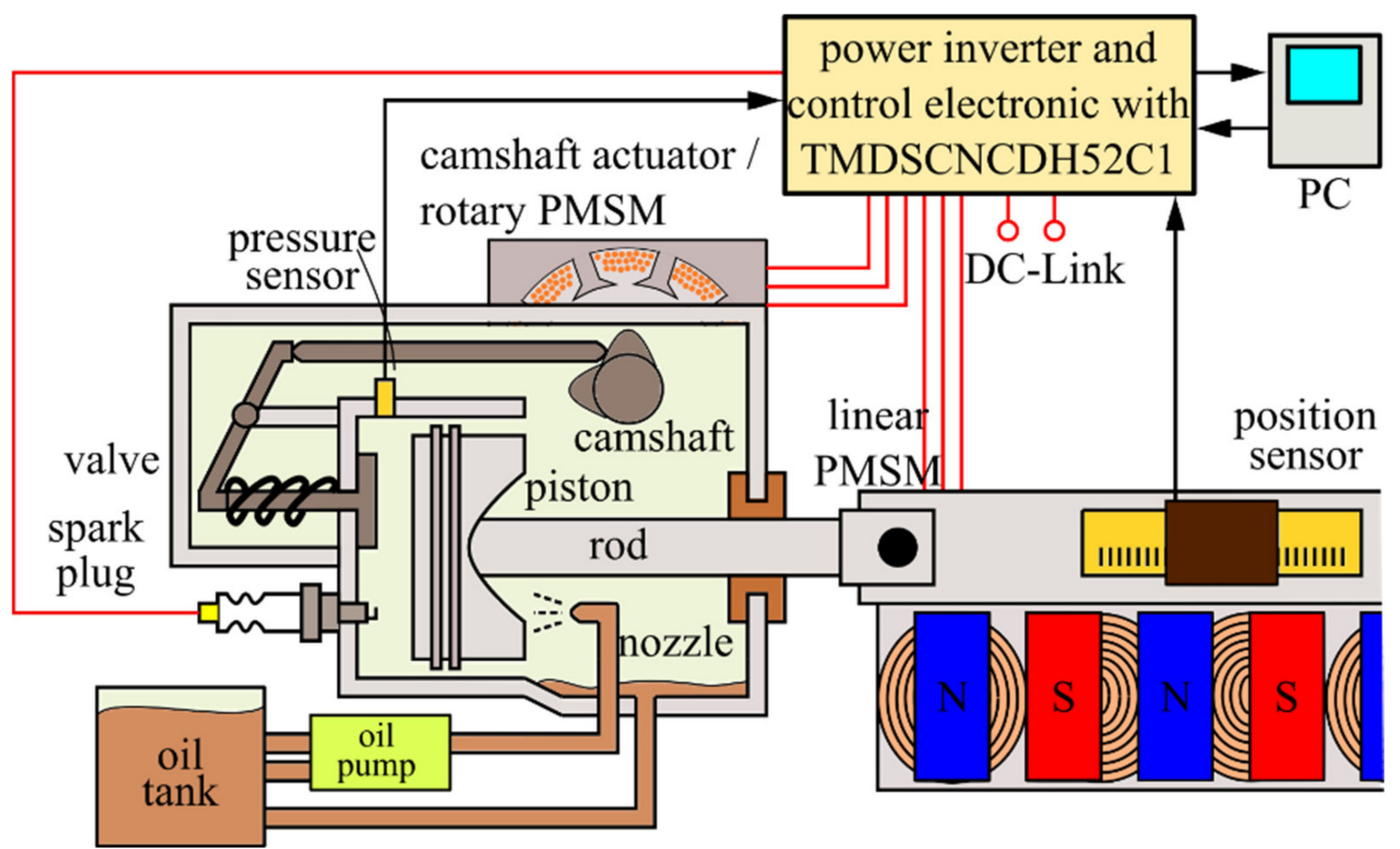

Figure 2. Schematic representation of the free-piston engine.

The internal combustion engine was originally used in a lawn mower. The crankshaft was removed and replaced with a piston and rod. This rod was passed out of the crankcase and connected to a linear electrical machine. The electrical machine is designed by the manufacturer Tecnotion $(2 \times U X X 6)$ as a permanent magnet excited synchronous machine (PMSM).

The mover of the electrical machine is ironless, where the primary part is moved. In this way, no cogging forces are present and the mass to be moved is low. The position of 
the electric machine was controlled using an inverter, a linear sensor and a microcontroller from Texas Instruments F28M35H52C. This microcontroller is able to calculate different trajectories, evaluate sensors and calculate manipulated variables (such as ignition sparks, injection times and transistor switch-on times). The data were then sent to a PC, saved and evaluated. The camshaft is connected to a highly dynamic PMSM. With the help of a valve drive, it is possible to operate the valves independently of the piston position. The camshaft and piston are synchronized digitally. To lubricate the cylinder surfaces, a nozzle was inserted which sprays a thin layer of oil under the piston. The most important parameters of the free-piston engine are shown in Table 1.

Table 1. Characteristic data of the test stand.

\begin{tabular}{cccc}
\hline \multicolumn{2}{c}{ Linear PMSM } & \multicolumn{2}{c}{ Combustion Engine } \\
\hline Rated Power & $3.24 \mathrm{~kW}$ & Engine Type & Four-Stroke \\
Rated Speed & $6.6 \mathrm{~m} / \mathrm{s}$ & Engine Displacement & $99.25 \mathrm{~cm}^{3}$ \\
Rated Current & $5.6 \mathrm{~A}_{\mathrm{rms}}$ & Rated Power & $1.9 \mathrm{~kW}$ \\
Peak Current & $28 \mathrm{~A}_{\mathrm{rms}}$ & Bore Diameter & $0.0554 \mathrm{~m}$ \\
Rated Force & $491 \mathrm{~N}$ & Number of Cylinders & 1 \\
Peak Force & $2455 \mathrm{~N}$ & Conventional Stroke & $0.0402 \mathrm{~m}$ \\
Mover Mass & $3.271 \mathrm{~kg}$ & Maximal Stroke & $0.0566 \mathrm{~m}$ \\
Mover Length & $0.505 \mathrm{~m}$ & Rated Speed & $4.27 \mathrm{~m} / \mathrm{s}$ \\
Magnet Yoke length & $0.627 \mathrm{~m}$ & Rated Force & $444.96 \mathrm{~N}$ \\
Maximum stroke & $0.122 \mathrm{~m}$ & Moving Mass & $0.286 \mathrm{~kg}$ \\
Resistance per phase & $1.29 \Omega$ & & \\
\hline
\end{tabular}

The problem with the electrical machine was that high copper losses occur when the four-stroke internal combustion engine is operated. It will be replaced with a selfdeveloped electric machine [29]. The primary part of the electrical machine is not moved. It has a flat geometry, a short stator and is double-sided. The essential characteristic data is illustrated in Figure 3 and shown in Table 2.

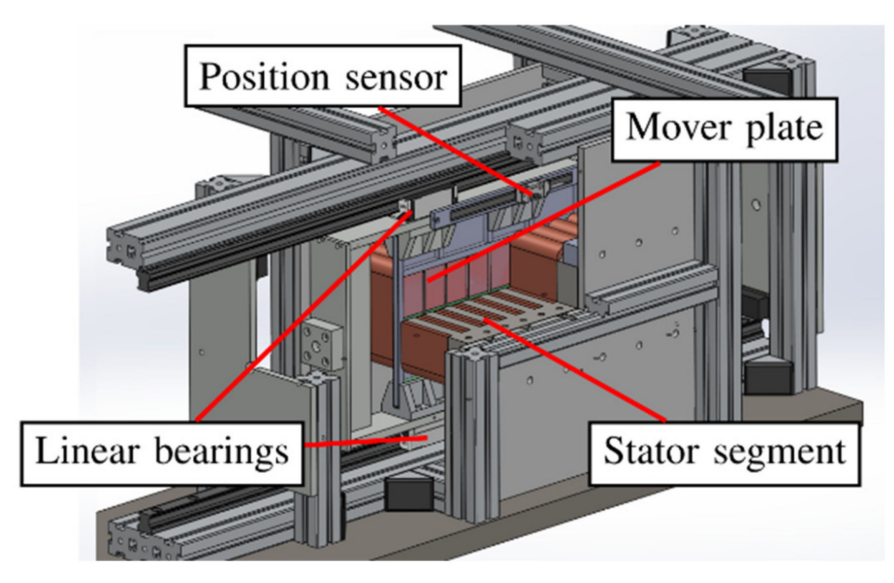

(a)

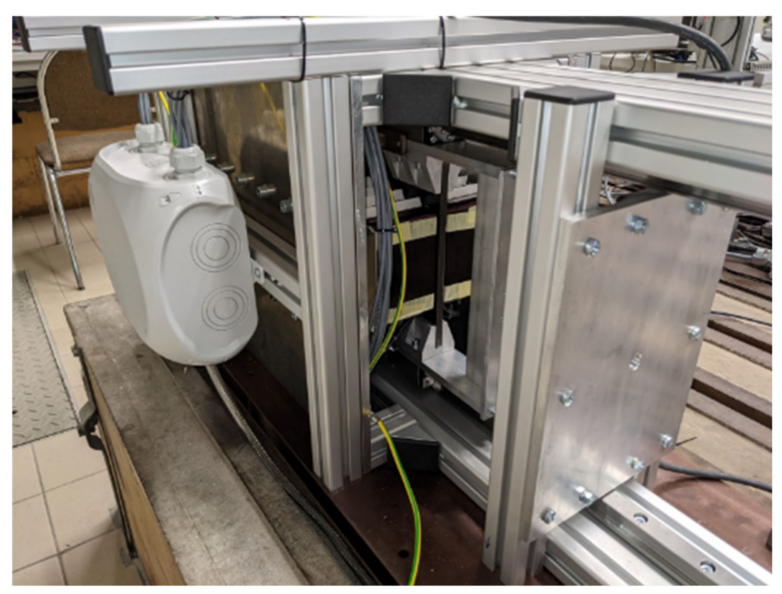

(b)

Figure 3. (a) CAD illustration of the developed electrical machine. (b) Photo of the developed electric machine.

The electrical machine was designed based on a measured force curve through the first prototype. A special feature of the electrical machine is that the primary part has the same length as the secondary part. This creates reluctance forces when the secondary part moves out of the stator. This force acts like a mechanical spring and can minimize copper losses. The reluctance force for this electrical machine is shown in Figure 4a. However, iron losses occur due to the magnetic structure. The iron power loss $P_{F e}$ was measured as a 
function of the electrical frequency $f_{e l}$ at various operating points and a function for this was approximated [35]. The function here corresponds to a Steinmetz model:

$$
P_{F e}=C_{h y} \cdot \hat{B}^{1,6} \cdot f_{e l}+C_{w b} \cdot \hat{B}^{2} \cdot f_{e l}^{2},
$$

where $\hat{B}$ is the magnetic flux density and $C_{h y}$ and $C_{w b}$ are two coefficients. The iron power loss is shown in Figure $4 \mathrm{~b}$.

Table 2. Characteristic data of the developed electrical machine.

\begin{tabular}{cc}
\hline & Linear PMSM \\
\hline Rated Power & $7.35 \mathrm{~kW}$ \\
Rated Speed & $2.26 \mathrm{~m} / \mathrm{s}$ \\
Rated Current & $16.55 \mathrm{~A}_{\mathrm{rms}}$ \\
Peak Current & $21.21 \mathrm{~A}_{\mathrm{rms}}$ \\
Rated Force & $3251 \mathrm{~N}$ \\
Peak Force & $3689 \mathrm{~N}$ \\
Mover Mass & $7.84 \mathrm{~kg}$ \\
Mover Length & $0.357 \mathrm{~m}$ \\
Magnet Yoke length & $0.357 \mathrm{~m}$ \\
Maximum stroke & $0.17 \mathrm{~m}$ \\
Resistance per phase & $0.441 \Omega$ \\
\hline
\end{tabular}

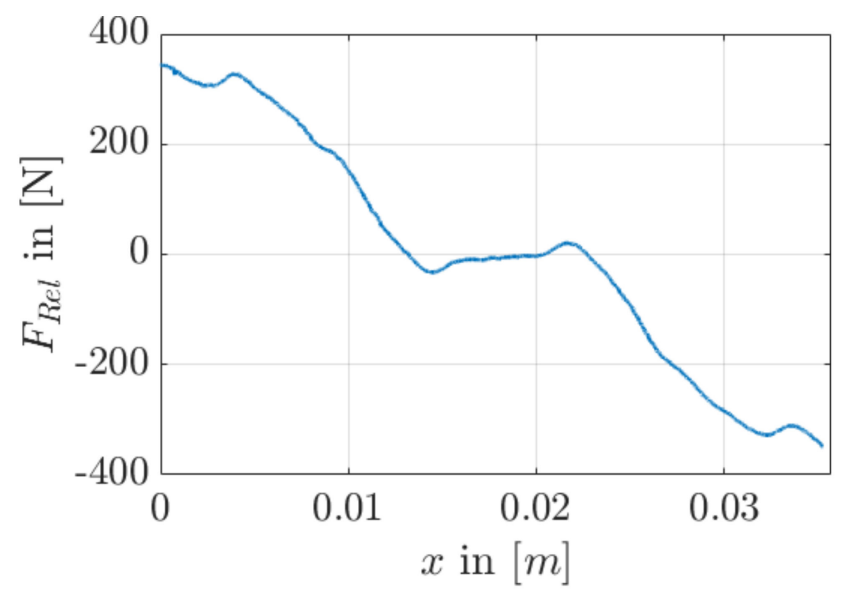

(a)

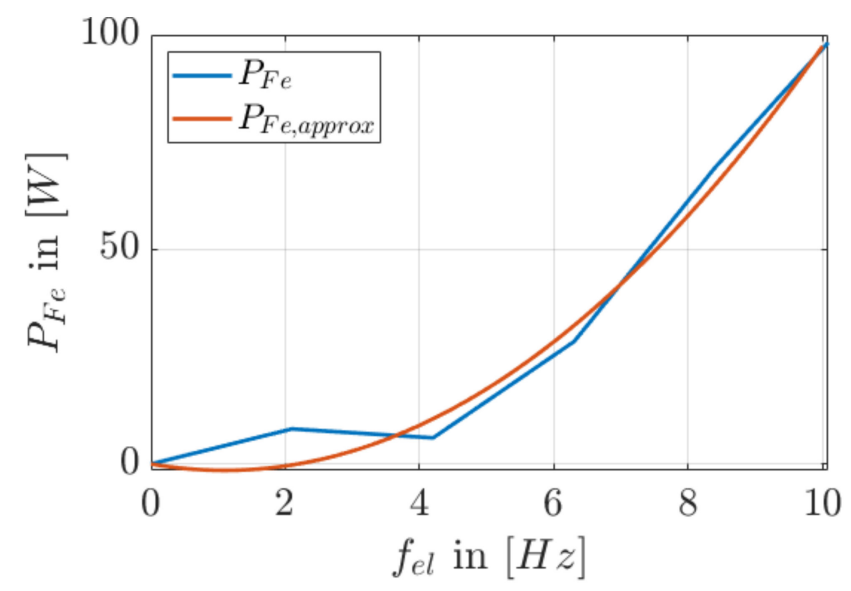

(b)

Figure 4. (a) Reluctance force $F_{R e l}$ depending on the position $x$. (b) Iron power losses $P_{F e}$ depending on frequency $f_{e l}$.

These special properties were inserted into a simulation model in order to determine the losses in the respective trajectories. For the simulations that were carried out, the parameters of the newly developed machine were used.

Since the secondary part moves out of the stator and the proportion of covered magnets to the windings is reduced, the magnetic flux is also reduced. This leads to a reduction in the induced voltage as well as to a reduction in the force per ampere ratio. Therefore, the force of the electrical machine depends on the position and current and is shown in Figure 5. It can be seen in Figure 5 that the force decreases at the stroke limits. 


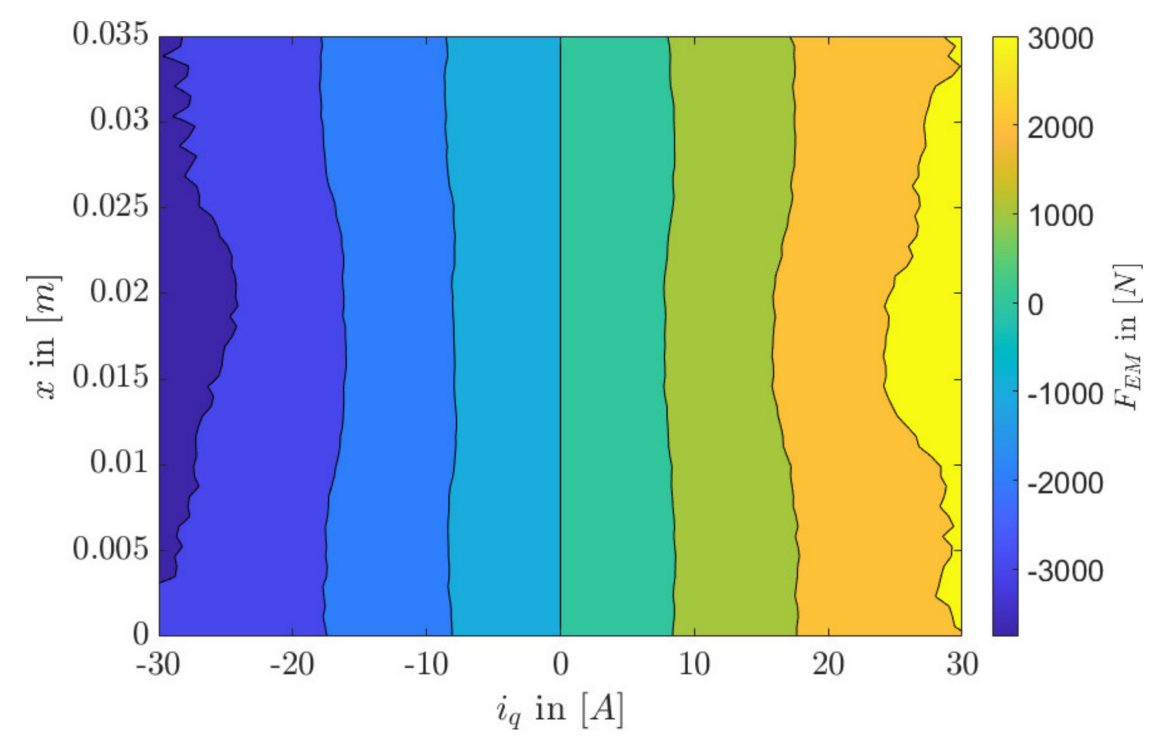

Figure 5. Force $F_{E M}$ depending on position $x$ and current $i_{q}$.

\section{Thermodynamic Model of the Free-Piston Engine}

Based on the data of Table 1, a one-dimensional thermodynamic model for the freepiston engine is built up. The combustion engine is working with an external mixture formation via a gasoline injector with a constant injected fuel mass in the intake manifold. The fuel mass is chosen this way so that the equivalence ratio $\phi=1$. This model of the free-piston engine is quite similar to an engine with a conventional crank train. To model the combustion process and the corresponding heat release, the predictive combustion model, the so-called Spark-Ignition Turbulent Flame Model (SITurb) from GT-Suite, was used. This model can be used for several operating points after it has been parameterized once. Additionally, it is normally used for gasoline engines, which is the test bench engine. The heat release is calculated by the burned fuel mass $m_{b}$ :

$$
\frac{d m_{b}}{d t}=\frac{m_{e}-m_{b}}{\tau}
$$

where $m_{e}$ is the entrained mass and $\tau$ is the time constant.

The entrained mass is calculated by:

$$
\frac{d m_{e}}{d t}=\rho_{u} \cdot A_{e} \cdot\left(S_{T}+S_{L}\right)
$$

where $\rho_{u}$ is the unburned density, $A_{e}$ is the surface area at flame front, $S_{T}$ is the turbulent flame speed and $S_{L}$ is the laminar flame speed.

The turbulent flame speed is calculated by:

$$
S_{T}=C_{T F S} \cdot u^{\prime} \cdot\left(1-\frac{1}{1+C_{F K G} \cdot\left(\frac{R_{f}}{L_{i}}\right)^{2}}\right)
$$

where $C_{T F S}$ is the turbulent flame speed multiplier, $u^{\prime}$ is the turbulent intensity, $C_{F K G}$ is the flame kernel growth multiplier, $R_{f}$ is the flame radius and $L_{i}$ is the integral length scale.

The laminar flame speed is calculated by:

$$
S_{L}=\left(B_{m}+B_{\phi} \cdot\left[\phi-\phi_{m}\right]^{2}\right) \cdot\left(\frac{T_{u}}{T_{r e f}}\right)^{\alpha_{e}} \cdot\left(\frac{p}{p_{r e f}}\right)^{\beta} \cdot f(\text { Dilution })
$$


where $B_{m}$ is the maximum laminar speed, $B_{\phi}$ is the laminar speed roll-off value, $\phi$ is the equivalence ratio, $\phi_{m}$ is the equivalence ratio at maximum speed, $T_{u}$ is the unburned gas temperature, $T_{r e f}$ is defined as $298 \mathrm{~K}, \alpha_{e}$ is the temperature exponent, $p$ is the pressure, $p_{r e f}$ is defined as $101,325 \mathrm{~Pa}$ and $\beta$ is the pressure exponent.

The heat transfer is defined by the WoschniClassic model from GT-Suite. This model is used for engines without swirl flows, which correspond to the test bench engine. First, a convective heat transfer is calculated; then, it is calibrated to the measurement data by a multiplier to take the influences of conduction and radiation into account. The heat transfer coefficient is calculated by:

$$
\alpha=\frac{K_{1} \cdot p^{0.8} \cdot w^{0.8}}{B^{0.2} \cdot T^{K_{2}}}
$$

where $K_{1}$ and $K_{2}$ are model constants, $p$ is the cylinder pressure, $w$ is the average cylinder gas velocity, $B$ is the cylinder bore and $T$ is the cylinder temperature. All multipliers are used to calibrate the model to the measurement data.

This heat transfer coefficient only takes the convection into account. To consider the influence of the radiation and conduction, an additional multiplier is used to calculate $\alpha$ for Equation (3).

The major difference of the model and the conventional engine models is the completely free definition of the piston motion. Specifically, the determination of the piston movement in the model is done via a table with free choice of the piston position as a function of time. In contrast to that, the piston motion normally is defined by the geometrical parameters of the crank train and the corresponding relation between crank angle and piston position. The thermodynamic model is illustrated in Figure 6. This model included the combustion and heat transfer process represented by the "cylinder" symbol and the mechanical components, which are represented by the "crank train" symbol. The boundary conditions of the incoming air and the outcoming exhaust gas are symbolized by the green symbols "inlet" and "outlet." The intake system consists of the inlet manifold, the inlet pipe, the throttle valve, the inlet channel, the injector and the inlet valve, as illustrated by the symbols on the left side of Figure 6. Thus, the engine works with an external mixture formation and a quantity control via the throttle valve. The symbols on the right side of Figure 6 represent the exhaust valve, the exhaust channel and the exhaust pipe.

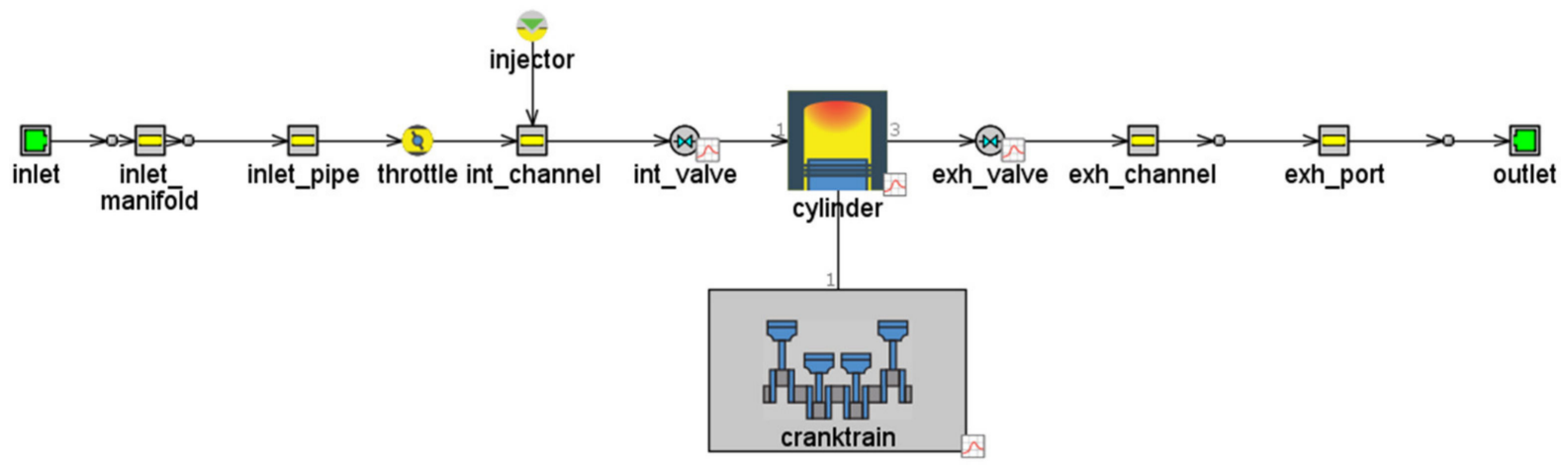

Figure 6. Thermodynamic model of a free-piston engine.

To analyze the influence of different trajectories on the thermodynamic losses, a stationary operating point is chosen and validated with test bench data. In the highpressure area, which represents the combustion in this operation point, the measurement and simulation data fit quite well (see Figure 7). 

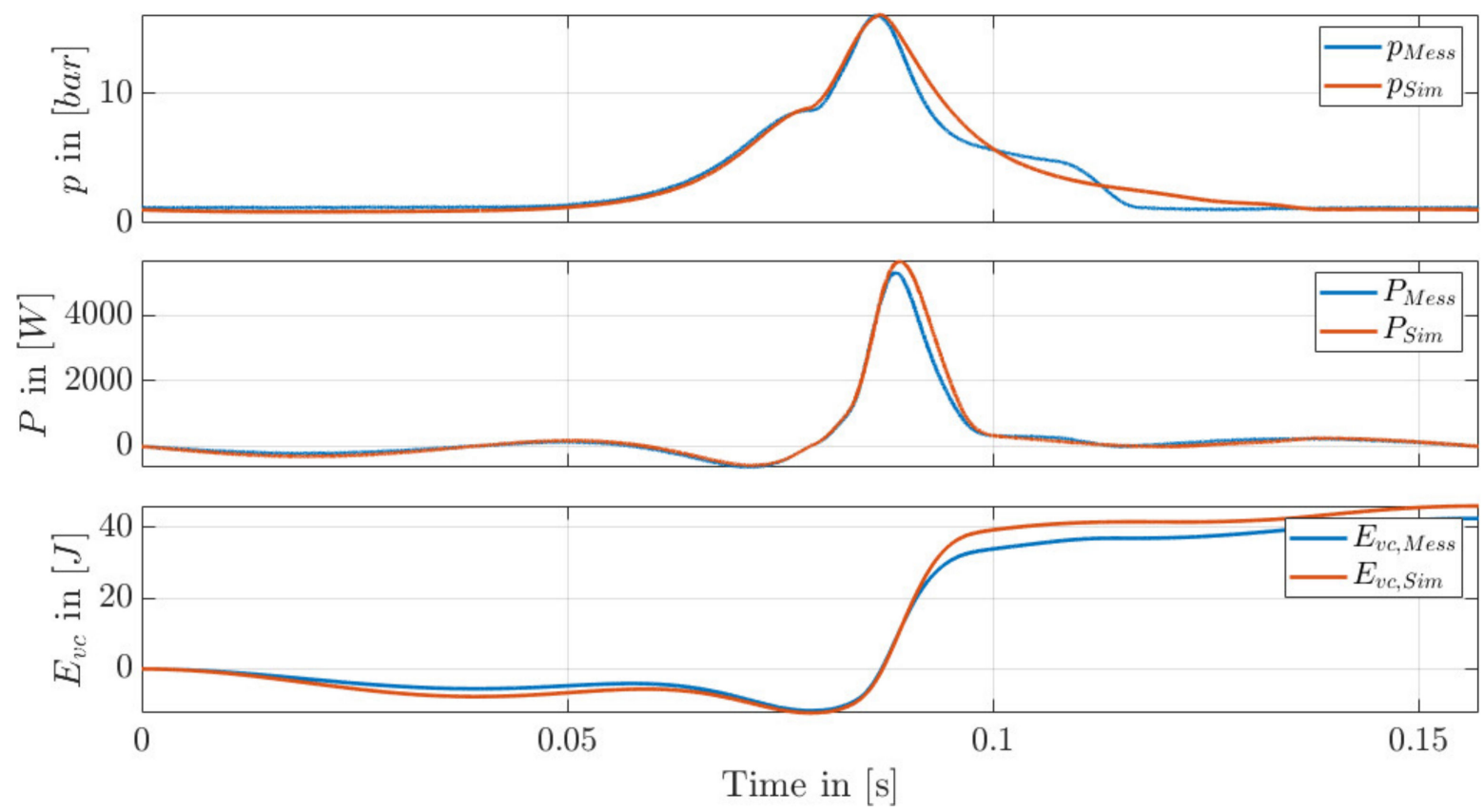

Figure 7. Comparison of the measured and simulated cylinder pressure, the engine power and the volume change energy.

This point, which is shown in Table 3, is located at an engine speed of $764 \mathrm{~min}^{-1}$ and an IMEP of 4.7 bar. The stroke is at an initial value of $0.03 \mathrm{~m}$ for the reverence trajectory, which leads to a compression ratio of 5.368. As fuel, the reference fuel indolene is used to describe automotive gasoline according to [36]. To model the combustion process, the already described predictive approach called "SI-Turb" is used, which describe the combustion by defining the turbulence intensity within the combustion chamber. The parameters, or rather the multipliers and their values which are used for this approach, are summarized in Table 3. The turbulent flame speed multiplier has influence on the turbulence level of the flame front during the combustion. The flame kernel growth multiplier describes how fast the flame kernel spreads during the combustion. With a higher multiplier of the Taylor length scale, the amount of time the air-fuel mixture is entrained into the flame front is decreased, which leads to short burning durations [37].

Table 3. Boundary conditions of the thermodynamic analysis.

\begin{tabular}{cccc}
\hline \multicolumn{2}{c}{ Combustion Engine } & Combustion Model: SI-Turb \\
\hline Engine Speed & $764 \mathrm{~min}^{-1}$ & Turbulent Flame Speed Multiplier & 0.025 \\
IMEP & $4.7 \mathrm{bar}$ & Flame Kernel Growth Multiplier & 0.01 \\
Injected fuel mass & $4.32 \mathrm{mg}$ & Taylor Length Scale Multiplier & 0.001 \\
Injected fuel & indolene & & \\
LHV of the fuel & $43.95 \mathrm{MJ} / \mathrm{kg}$ & & \\
Initial Stroke & $0.03 \mathrm{~m}$ & & \\
Effective compression ratio & 5.368 & \\
\hline
\end{tabular}

\section{Simulation Model of the Linear Permanent Magnet Synchronous Machine}

The mentioned properties of the electrical machine were implemented in a simulation model. The simulation model for this is shown schematically in Figure 8.

The acceleration force $F_{A C C}$ is calculated with the acceleration $a$ and the mass $m$. The gas force $F_{I C E}$ is calculated from the product of cylinder pressure $p$ and area $A_{c y l}$. It is possible to determine the reluctance force $F_{R e l}$ from the position $x$ and the course from Figure 4a. The frictional force was neglected. With the help of these forces, the force of the electrical machine is calculated. The map from Figure 5 is then used to calculate the target current from the force $F_{E M}$ and the position $x$. The copper power loss $P_{C u}$ can be calculated 
from the current $i_{q}$ and ohmic resistance $R$. The mechanical power of the electrical machine $P_{M}$ can be determined from the force $F_{E M}$ and the speed $v$. The iron losses $P_{F e}$ can be calculated from the electrical frequency $f_{e l}$ and the map from Figure 4. The sum of all powers results in the electrical power.

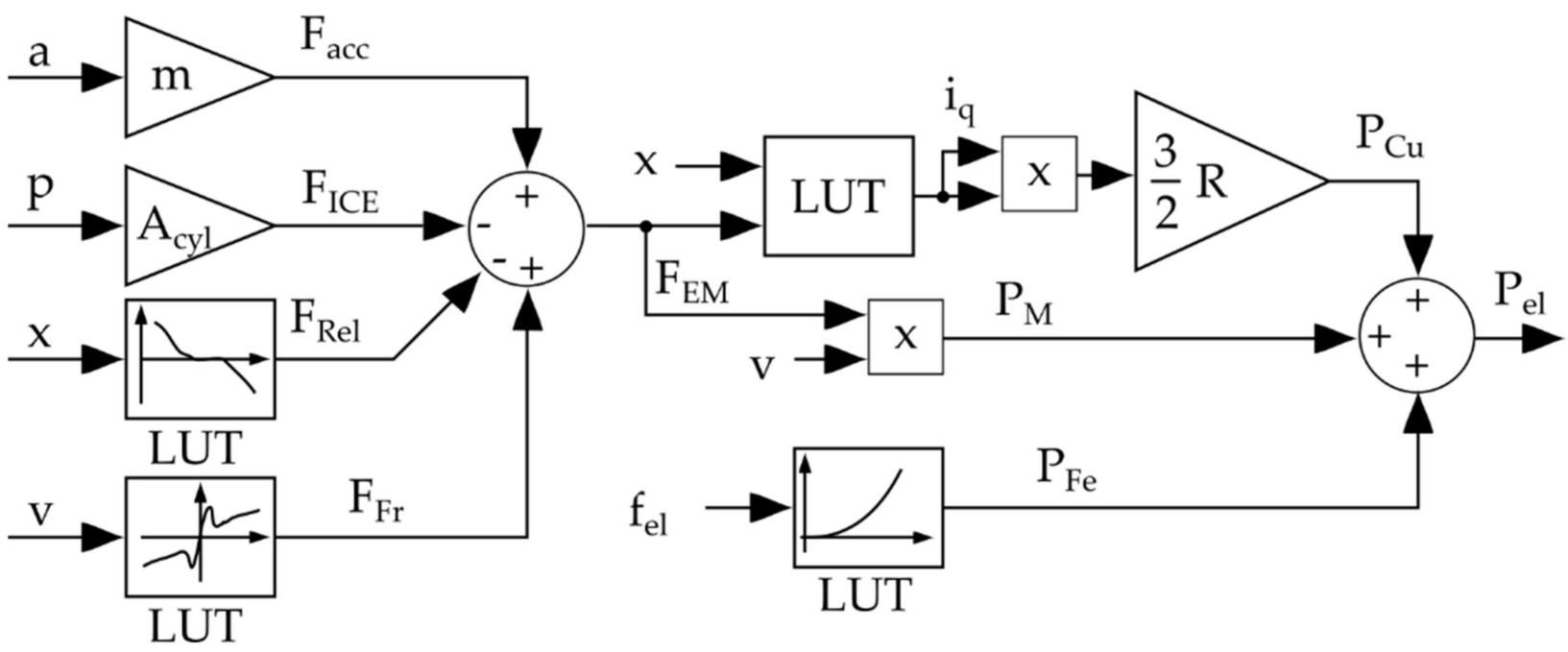

Figure 8. Simplified simulation model of the LMPSM.

\section{Trajectory Variation}

\subsection{Specificity of the Free-Piston Engine}

The free-piston engine allows the piston stroke to be adjusted in a highly dynamic manner so that different trajectories can be followed. For practical implementation, care must be taken that there are no discontinuities in the acceleration, as this on the one hand cannot be implemented and on the other hand represents a high load on the drive train. Furthermore, it is advantageous for the trajectory variation if it can be described analytically. Here, various parameters can be set that can specifically adapt the shape of the trajectory. In the following sections, various functions will be presented which allow the piston stroke course to be adjusted.

\subsection{Reference Stroke}

A sinusoidal curve is used to compare the trajectories. The trajectory can be described analytically as follows:

$$
\begin{gathered}
x=-\frac{x_{\text {peak }}}{2} \cdot \cos (\varphi)+\frac{x_{\text {peak }}}{2} \\
v=\frac{x_{\text {peak }} \cdot \frac{d \varphi}{d t}}{2} \cdot \sin (\varphi) \\
a=\frac{x_{\text {peak }} \cdot \frac{d \varphi^{2}}{d t}}{2} \cdot \cos (\varphi)+\frac{x_{\text {peak }}}{2} \cdot \frac{d^{2} \varphi}{d t^{2}} \cdot \sin (\omega t)
\end{gathered}
$$

The first and second derivatives of the stroke with respect to time result in the velocity and acceleration. For the four strokes, it is assumed that the stroke amplitude $x_{\text {peak }}$ and the virtual angular velocity $\omega$ do not change (Assumption: $\omega=$ const.). The used reference trajectory is shown in Figure 9. 


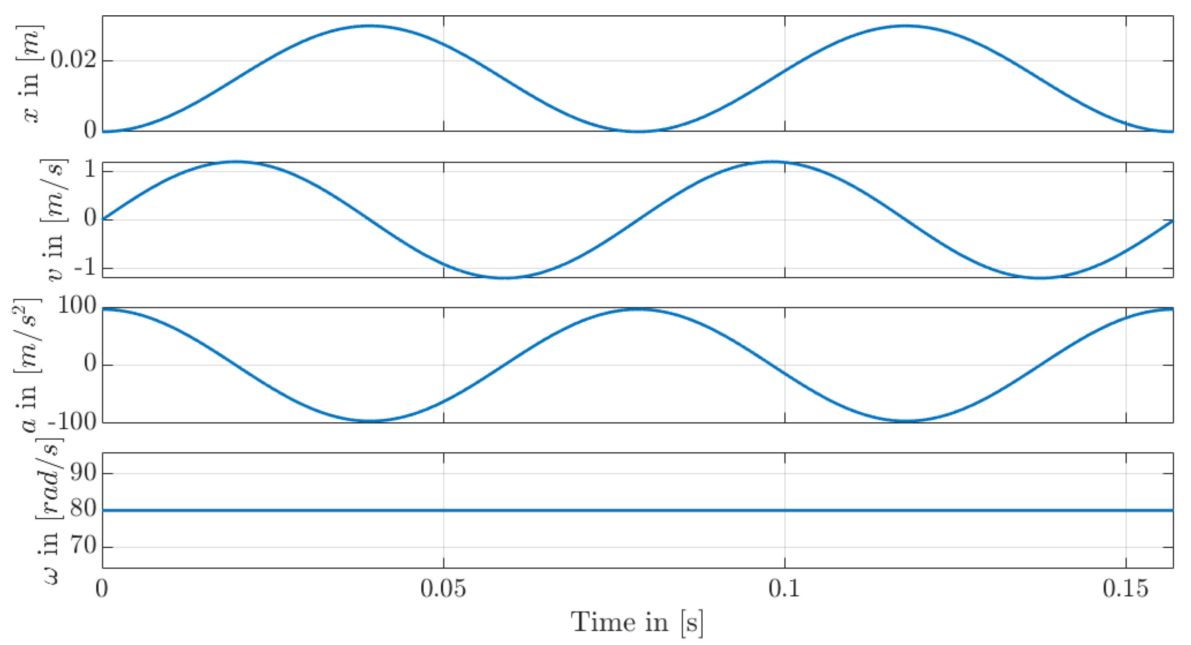

Figure 9. Sinusoidal trajectory for the four strokes with the parameters $x_{\text {peak }}=0.03 \mathrm{~m}$ and $\omega=80 \frac{\mathrm{rad}}{\mathrm{s}}$ depending on time.

As can be seen here, the time intervals for the TDC, BDC and the stroke amplitude are constant and the change in the piston position is very symmetrical. This trajectory is used in the following as a reference trajectory in order to show the changes in the piston position.

\subsection{Time Displacement of the Dead Center (Trajectory A)}

First, a function has to be determined with which the duration of one stroke can be changed without changing the period duration of the four strokes. The following individual stroke duration $\left(T_{i}\right)$ and their setting parameters $\left(\Delta T_{i, r e l}\right)$ are defined depending on the period time $T_{P}$ :

$$
\begin{gathered}
T_{1}=\Delta T_{1, \text { rel }} \cdot T_{P} \\
T_{2}=\Delta T_{2, \text { rel }} \cdot T_{P} \\
T_{3}=\Delta T_{3, \text { rel }} \cdot T_{P} \\
T_{4}=T_{P}-T_{1}-T_{2}-T_{3}
\end{gathered}
$$

To change the duration of a stroke, the average angular speed of one stroke must be adjusted. In addition, the transition between the cycles must take place without discontinuities in the acceleration. This is achieved in that the initial angular speed $\omega_{\text {Begin }}$ is identical to the final speed $\omega_{E n d}$ and the average speed $\omega_{P}$ over the four cycles:

$$
\omega_{\text {Begin }}=\omega_{\text {End }}=\omega_{P}=\frac{4 \pi}{T_{P}} .
$$

These conditions can be met with various functions. A sinusoidal change was chosen to implement the time displacement. The mean value of a half sine wave can be calculated as follows:

$$
\bar{\omega}_{i}=\frac{1}{\pi} \int_{0}^{\pi} \hat{\omega}_{i} \cdot \sin (\varphi) d \varphi=\frac{2}{\pi} \hat{\omega}_{i}=\frac{\pi}{T_{i}} .
$$

In order to meet the boundary conditions, the sine function has to be shifted by $\omega_{P}$ :

$$
\omega=\frac{\pi}{2} \cdot\left(\bar{\omega}_{i}-\omega_{P}\right) \cdot \sin \left(t \bar{\omega}_{i}\right)+\omega_{P} .
$$

The integration of Equation (33) results in the angle $\varphi$, which can be used in Equations (24) and (25) in order to obtain an analytical description of the speed and acceleration. The trajectory for the dead center shift is shown in Figure 10. 


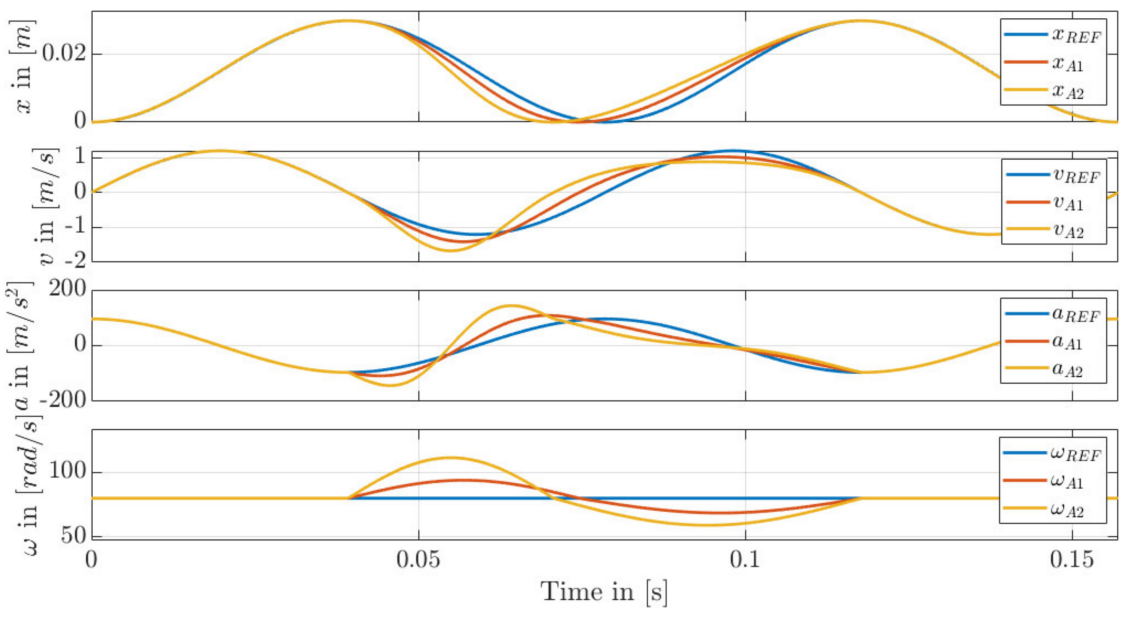

Figure 10. Comparison between the reference curve and dead center shift in the operating point $\omega=80 \frac{\mathrm{rad}}{\mathrm{s}}, x_{\text {peak }}=0.03 \mathrm{~m}, T_{1}=0.25 \cdot T_{p}, T_{2}=0.225 \cdot T_{p}, T_{3}=0.275 \cdot T_{p}$ and $\omega=80 \frac{\mathrm{rad}}{\mathrm{s}}$, $x_{\text {peak }}=0.03 \mathrm{~m}, T_{1}=0.25 \cdot T_{p}, T_{2}=0.2 \cdot T_{p}, T_{3}=0.3 \cdot T_{p}$.

With the advanced features, it is possible to vary the period of three cycles. The period of the fourth cycle is calculated from the specified period for the entire cycle.

\subsection{Compression and Extension of the Stroke (Trajectory B)}

Furthermore, it was investigated how the variation of the piston holding time affects the combustion process. For this, it was necessary to develop a function with which it should be possible to compress or stretch the stroke curve without changing the temporal position of the dead centers. The piston stroke trajectory can be varied by changing the virtual angular velocity during a cycle. The position of the dead centers can be kept constant if the mean angular velocity remains the same. A sinusoidal modulation was also chosen here:

$$
\omega=\Delta \omega_{T i} \cdot \sin (2 \varphi)+\omega_{P}
$$

where $\Delta \omega_{T i}$. is an adjustable parameter which corresponds to the amplitude of the superimposed sinusoidal oscillation from the i-th stroke. The frequency is twice as high so that the mean value is not changed within one stroke. A combination of the method for shifting the dead centers is also possible. All you have to do is replace $\omega_{P}$ with $\bar{\omega}_{i}$. The trajectory for a stroke compression and extension is shown in Figure 11.

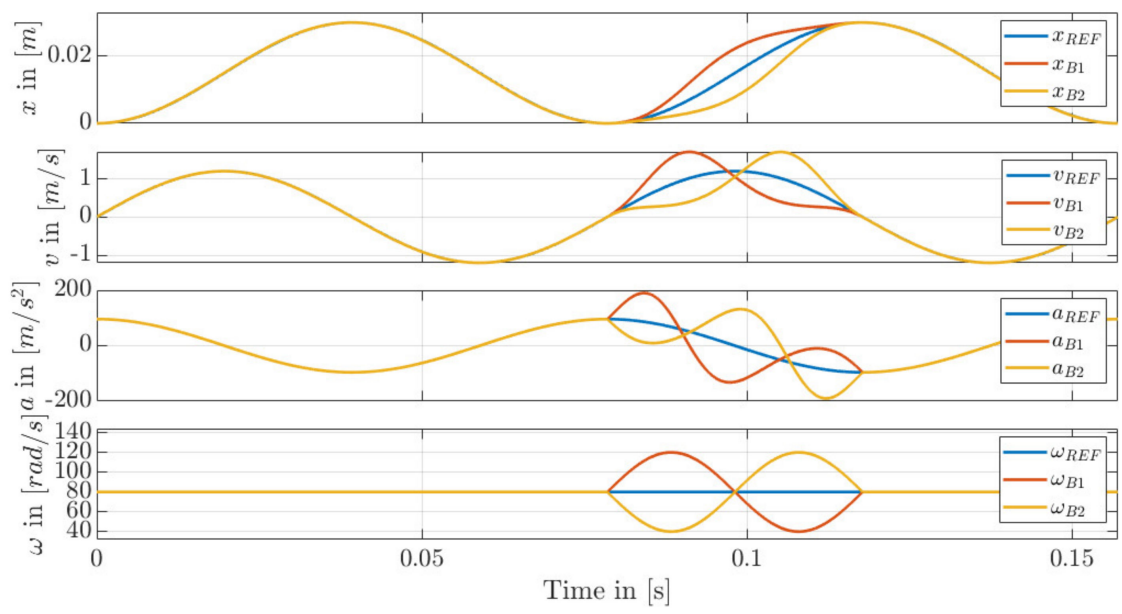

Figure 11. Comparison between the reference curve and compression and extension in the operating point $\omega=80 \frac{\mathrm{rad}}{\mathrm{s}}, x_{\text {peak }}=0.03 \mathrm{~m}, \Delta \omega_{T 1}=0 \frac{\mathrm{rad}}{\mathrm{s}}, \Delta \omega_{T 2}=0 \frac{\mathrm{rad}}{\mathrm{s}}, \Delta \omega_{T 3}=40 \frac{\mathrm{rad}}{\mathrm{s}}, \Delta \omega_{T 4}=0 \frac{\mathrm{rad}}{\mathrm{s}}$ and $\omega=80 \frac{\mathrm{rad}}{\mathrm{s}}, x_{\text {peak }}=0.03 \mathrm{~m}, \Delta \omega_{T 1}=0 \frac{\mathrm{rad}}{\mathrm{s}}, \Delta \omega_{T 2}=0 \frac{\mathrm{rad}}{\mathrm{s}}, \Delta \omega_{T 3}=-40 \frac{\mathrm{rad}}{\mathrm{s}}, \Delta \omega_{T 4}=0 \frac{\mathrm{rad}}{\mathrm{s}}$. 
It can be seen in Figure 11 that the piston stroke trajectory can be changed significantly without changing the position of the dead centers. It can also be seen here that the acceleration has no points of discontinuity.

\subsection{Variation of the Stroke Amplitude (Trajectory C)}

The adjustment of the stroke amplitude is another interesting degree of freedom for modulating the trajectory. The position of the top dead center was left constant and the bottom dead center was shifted. The piston stroke has already been described analytically with Equation (24). If $x_{\text {peak }}$ is changed here, it is possible to vary the target trajectory. This change in stroke should also take place in such a way that there are no discontinuities in the acceleration. Various functions can be used for this. A sinusoidal change in the stroke amplitude was decided:

$$
\mathrm{x}_{\text {peak }}=-\frac{\hat{x}_{1}-\hat{x}_{2}}{2} \cdot \sin \left(\frac{\varphi}{2}\right)+\frac{\hat{x}_{1}-\hat{x}_{2}}{2} .
$$

where $\hat{x}_{2}$ corresponds to the stroke amplitude at the bottom dead center between the intake and compression stroke and $\hat{x}_{1}$ is the stroke amplitude at the bottom dead center between the expansion and exhaust stroke. The trajectory is shown in Figure 12.

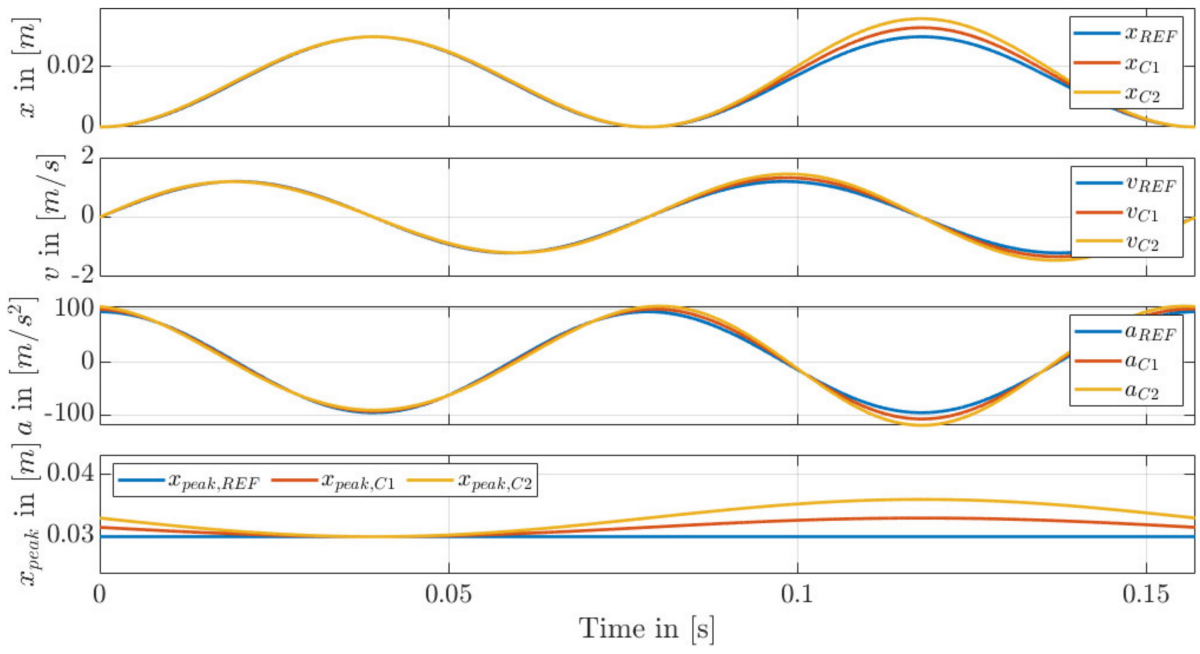

Figure 12. Comparison between the reference curve and stroke amplitude variation in the operating point $\omega=80 \mathrm{rad} / \mathrm{s}, \hat{x}_{1}=0.03 \mathrm{~m}, \hat{x}_{2}=0.033 \mathrm{~m}$ and $\omega=80 \mathrm{rad} / \mathrm{s}, \hat{x}_{1}=0.03 \mathrm{~m}, \hat{x}_{2}=0.036 \mathrm{~m}$.

As can be seen here, the different stroke amplitudes can be set separately from one another. In addition, no steps in acceleration can be seen here either, so practical implementation is possible.

\subsection{Combination of Proposed Trajectories (Trajectory D)}

As the last type of variation, it is shown that it is possible to combine the mentioned trajectory generation methods. It was decided to adjust the position of the TDC and to increase the acceleration of the piston after the TDC. The trajectories can be calculated as a combination of the methods from Sections 6.3 and 6.4. The trajectory is shown in Figure 13. 


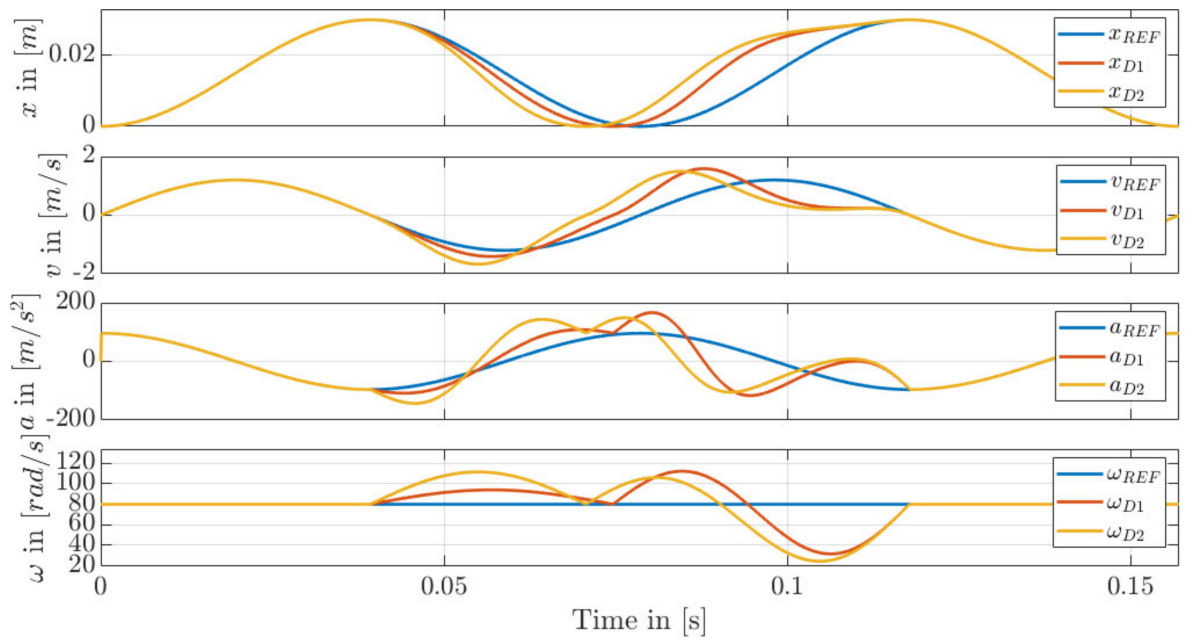

Figure 13. Comparison between the reference curve and stroke amplitude variation in the operating point $\omega=80 \mathrm{rad} / \mathrm{s}, x_{\text {peak }}=0.03 \mathrm{~m}, T_{2}=0.225 \cdot T_{p}, T_{3}=0.275 \cdot T_{p}, \Delta \omega_{T 3}=40 \frac{\mathrm{rad}}{\mathrm{s}}$ and $\omega=80 \mathrm{rad} / \mathrm{s}$, $x_{\text {peak }}=0.03 \mathrm{~m}, T_{2}=0.2 \cdot T_{p}, T_{3}=0.3 \cdot T_{p}, \Delta \omega_{T 3}=40 \frac{\mathrm{rad}}{\mathrm{s}}$.

\section{Results}

This chapter shows the results of the efficiency loss analysis for the trajectory variation. The losses of the internal combustion engine and the electrical machine were shown together in a diagram in order to evaluate the influence of the trajectory. For the evaluation of the energy conversion from chemical to mechanical energy the courses for the piston motion, the corresponding pressure and temperature as well as a PV diagram of the compared trajectories will be shown and discussed. For the energy conversion from mechanical to electrical energy, the position and speed of the piston, the electrical machine force and the resulting power are shown and discussed.

The loss analysis for the reference is shown in Figure 14. The summation of all energy shares is the chemical energy from the fuel. This energy is divided into the losses for unburned fuel, the wall heat losses, the losses inside the exhaust gas, the friction losses, the iron losses and the copper losses. The last share is the electrical energy, which is issued by the free-piston engine.

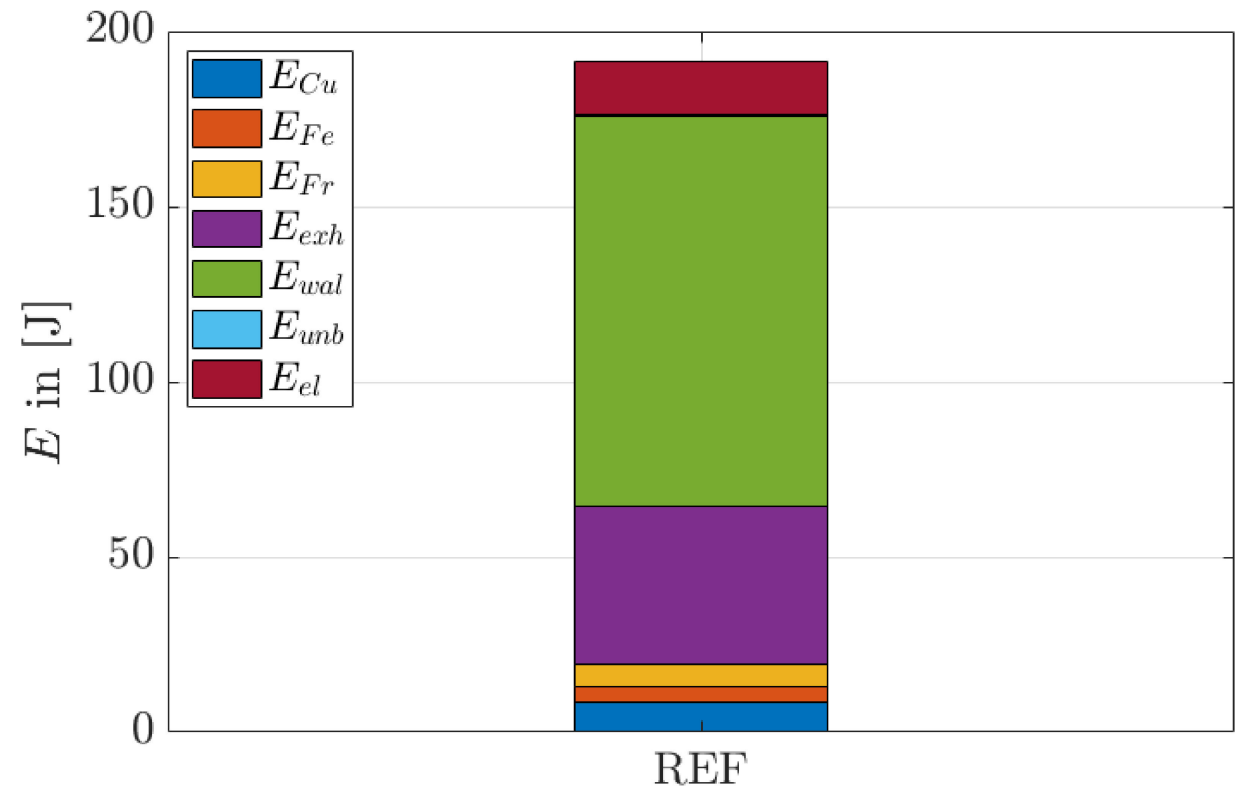

Figure 14. Energy losses for trajectory REF. 
Corresponding to the trajectory variation described in Section 6, the courses for the piston motion, the pressure and temperature are shown in Figure 15. The PV diagram for variant A1 and A2 in comparison to the reference is shown in Figure 16. The moved position in time of top dead center firing (TDCF) affects the pressure and temperature courses identically. The moved TDCF of variant A1 and A2 leads to earlier increasing pressure and temperature in comparison to the reference due to the fact that the combustion is initialized early. The decrease of the pressure and temperature is shifted in parallel. At the end of the expansion stroke all courses approach until the exhaust valve opens (EVO). After that, the courses are similar.
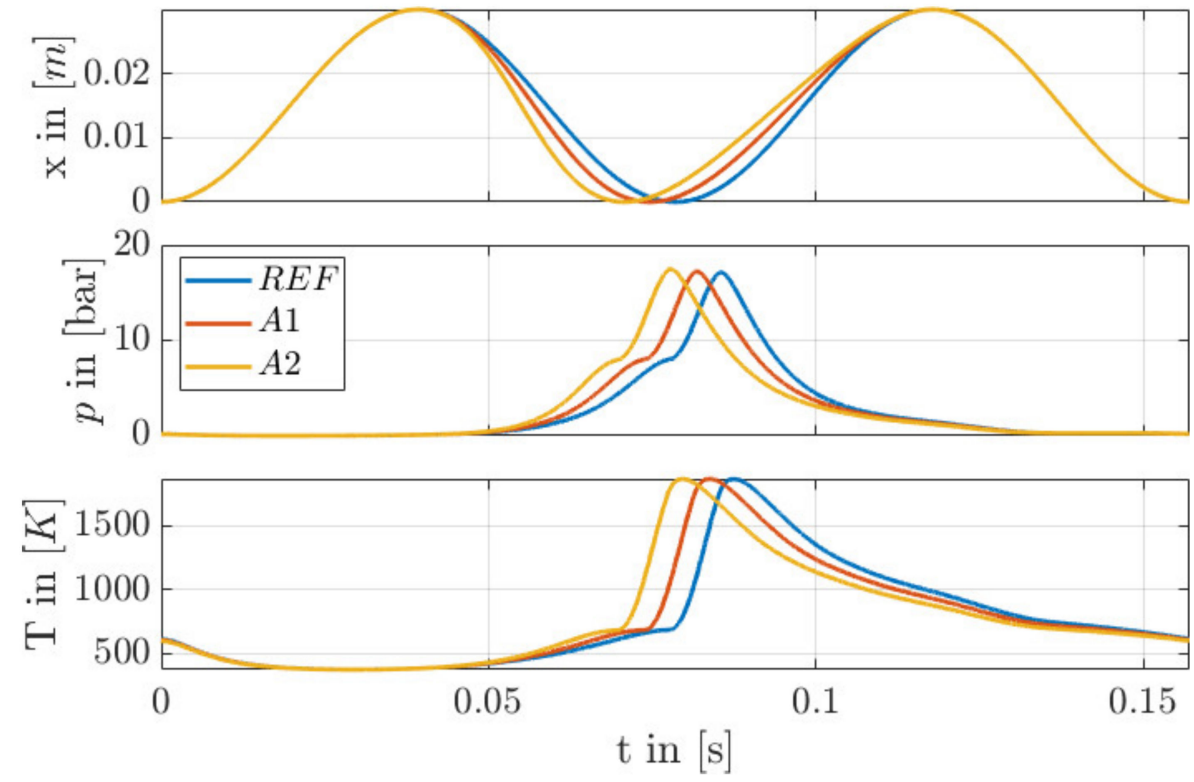

Figure 15. Comparison of trajectories REF, A1 and A2 related to the energy conversion of the internal combustion engine: illustration of the stroke, cylinder pressure and temperature depending on time.

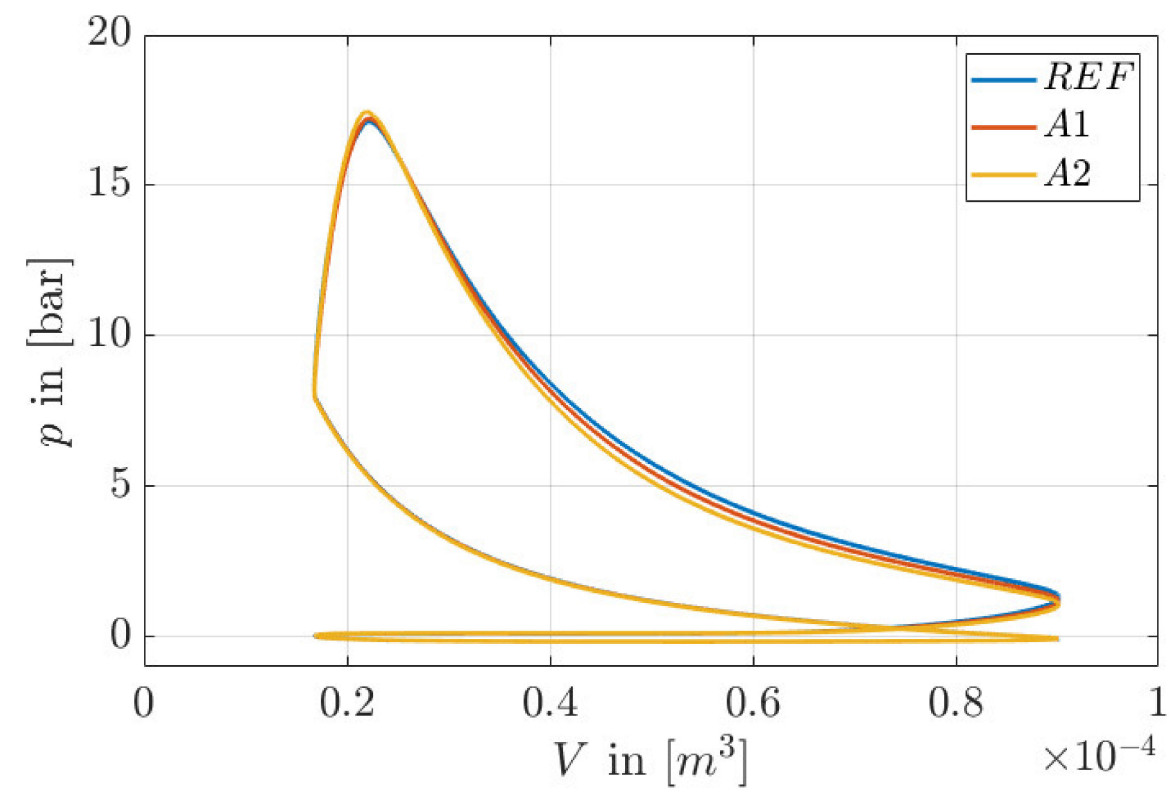

Figure 16. Comparison of trajectories REF, A1 and A2 related to the energy conversion of the internal combustion engine: cylinder pressure depending on volume. 
For the evaluation of the electrical energy conversion of the trajectory REF, A1, A2, the stroke, speed and force of the electrical machine are shown in Figure 17 and the volume change, copper, friction and electrical power in Figure 18.
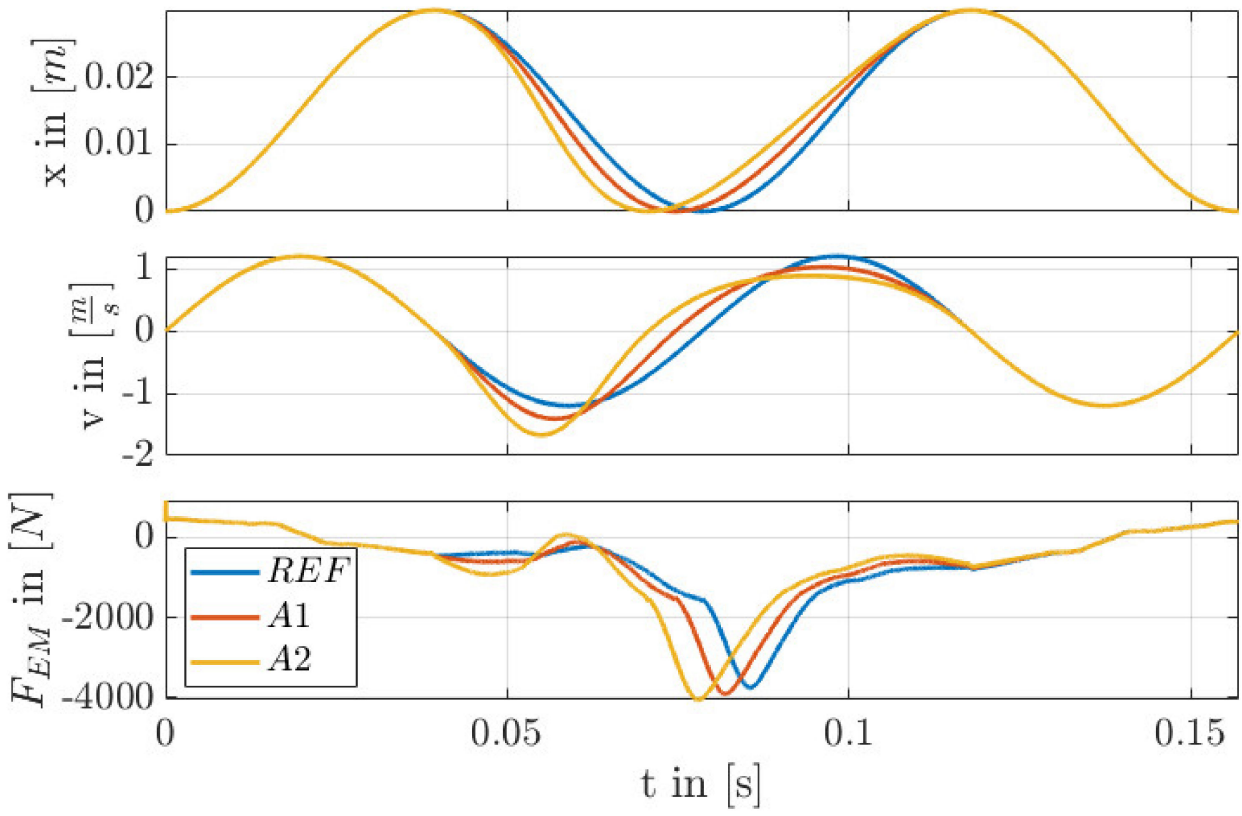

Figure 17. Comparison of trajectories REF, A1 and A2 related to the energy conversion of the electrical machine: illustration of the stroke, velocity and electric machine force depending on time.

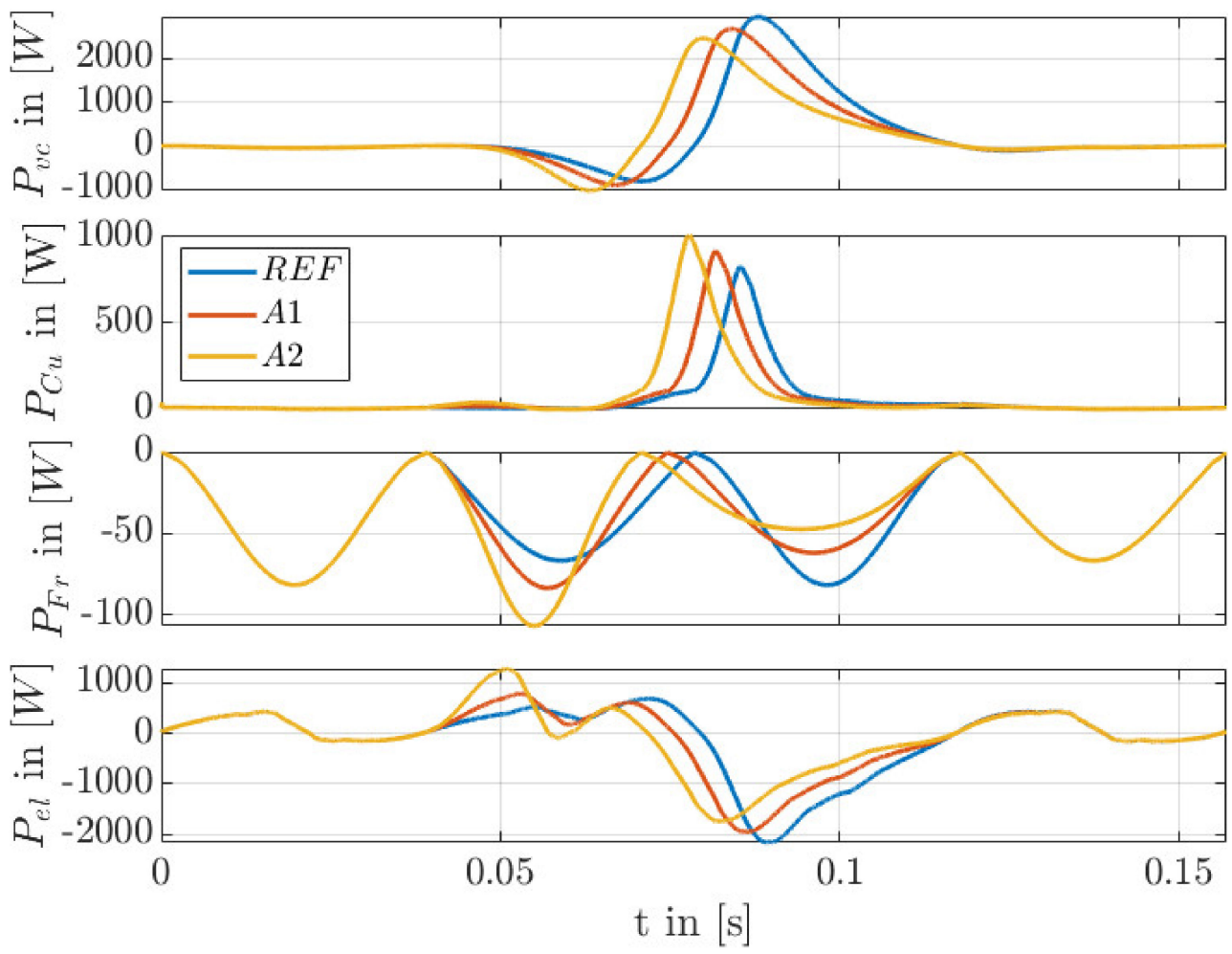

Figure 18. Comparison of trajectories REF, A1 and A2 related to the energy conversion of the electrical machine: volume change power, copper power losses, friction power losses and electric power depending on time. 
The shift of the trajectory from REF to A2 is realized by further accelerating the drive train. The required trajectory can be implemented using the force $F_{E M}$ of the electrical machine. Due to the increased force $F_{E M}$, the required current and, thus, the copper losses $P_{C u}$ increase. Since the speed is increased, the friction losses also increase. In addition to the volume change work, it can be seen that the electrical machine requires energy in the intake and exhaust cycle so that the four-cycle process can be implemented.

The longer expansion time with a higher temperature and similar pressure leads to the higher wall heat losses and reduced exhaust losses shown in Figure 19. This phenomenon can be seen when moving the TDCF to an earlier point in time. Due to the fact that the increase of the wall heat losses combined with the copper losses is higher than the decrease of the exhaust losses, both variants show a lower effective efficiency than the reference.

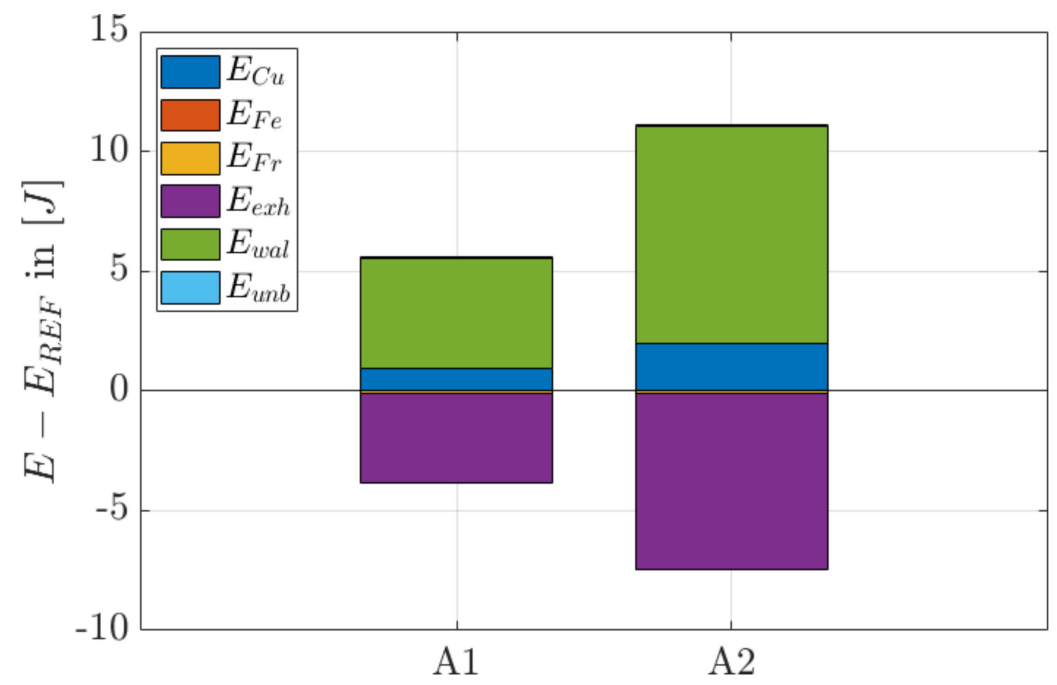

Figure 19. Energy losses for trajectory A1 and A2 with respect to REF.

The courses for the piston motion, the pressure and temperature are shown in Figure 20. The PV diagram for variant B1 and B2 in comparison to the reference is shown in Figure 21.
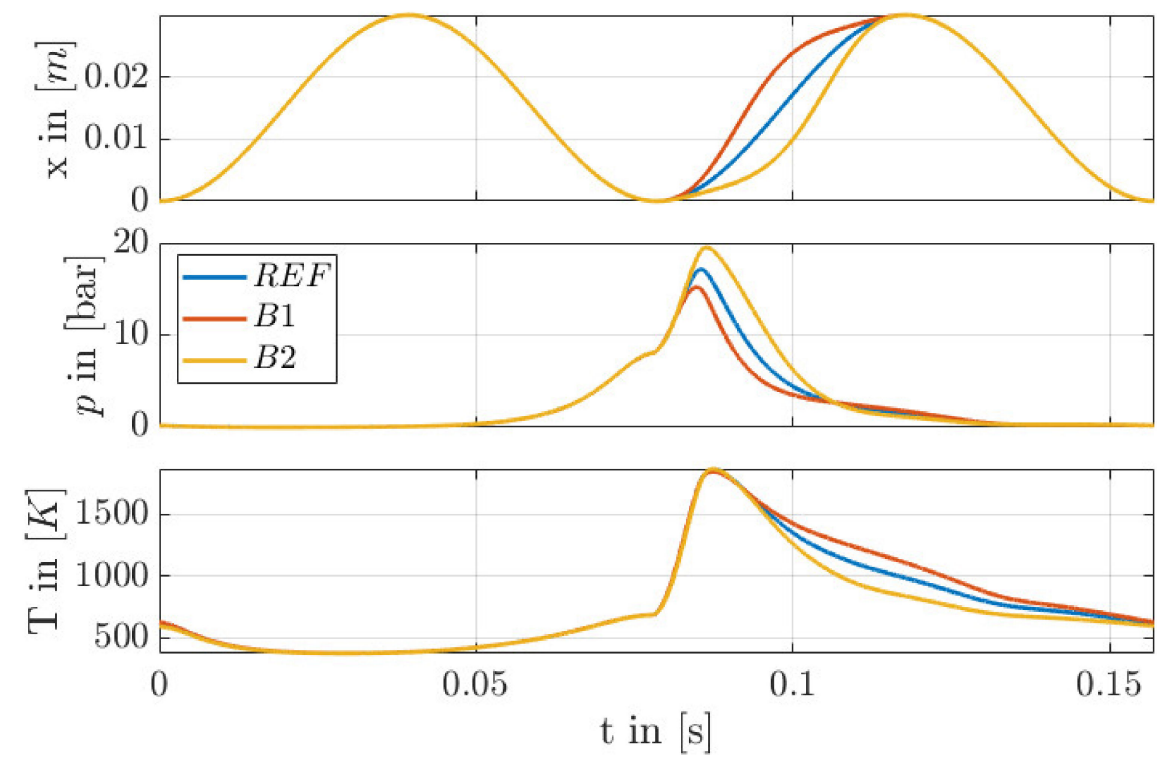

Figure 20. Comparison of trajectories REF, B1 and B2 related to the energy conversion of the internal combustion engine: illustration of the stroke, cylinder pressure and temperature depending on time. 


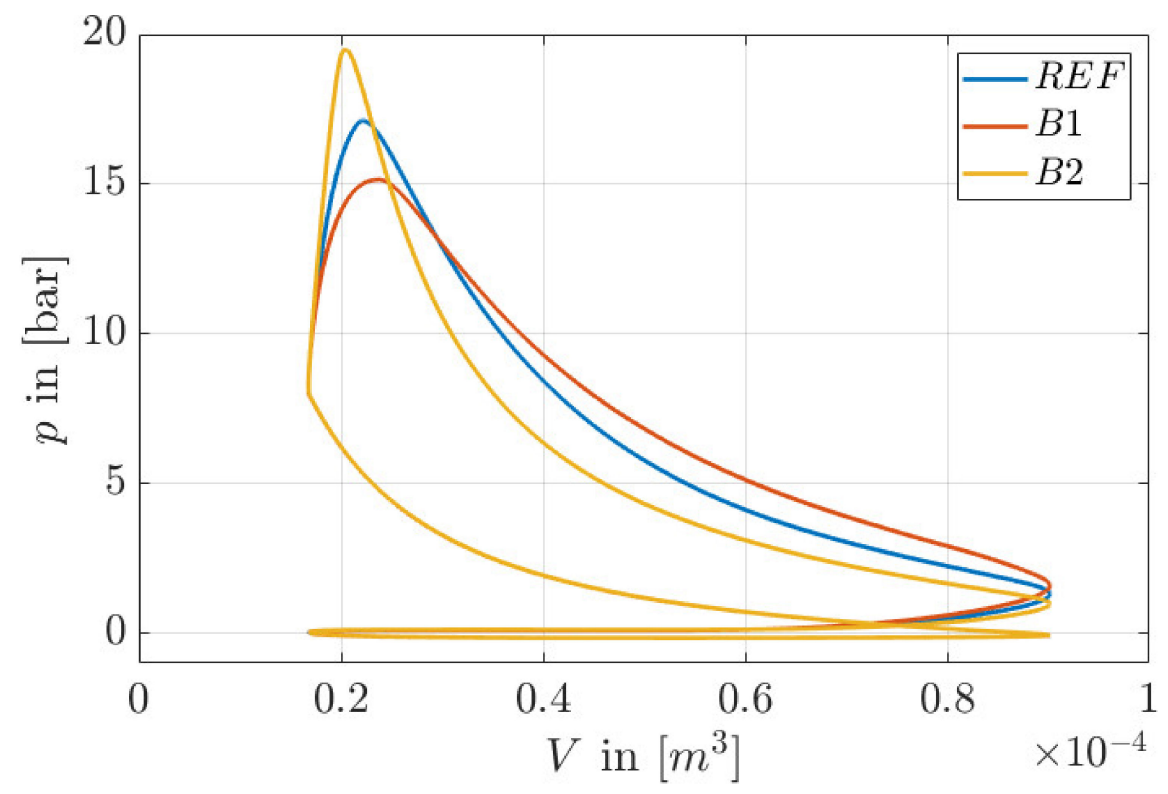

Figure 21. Comparison of trajectories REF, B1 and B2 related to the energy conversion of the internal combustion engine: cylinder pressure depending on volume.

The variant $\mathrm{B} 1$ has an increased acceleration of the piston during the expansion close to the TDCF and a reduced acceleration near the BDC. Variant B2 is exactly flipped. This leads to a decrease of the peak pressure near TDCF for B1 and an increased peak pressure for B2. Near BDC, the opposite behavior can be observed. The maximum temperature is not influenced by the different variation of the piston acceleration. The decrease of the temperature from TCDF to BDC is slower for variant B1 and faster for variant B2 in comparison to the reference.

For the evaluation of the electrical energy conversion of the trajectory REF, B1, B2, the stroke, speed and force of the electrical machine are shown in Figure 22 and the volume change, copper, friction and electrical power are shown in Figure 23.
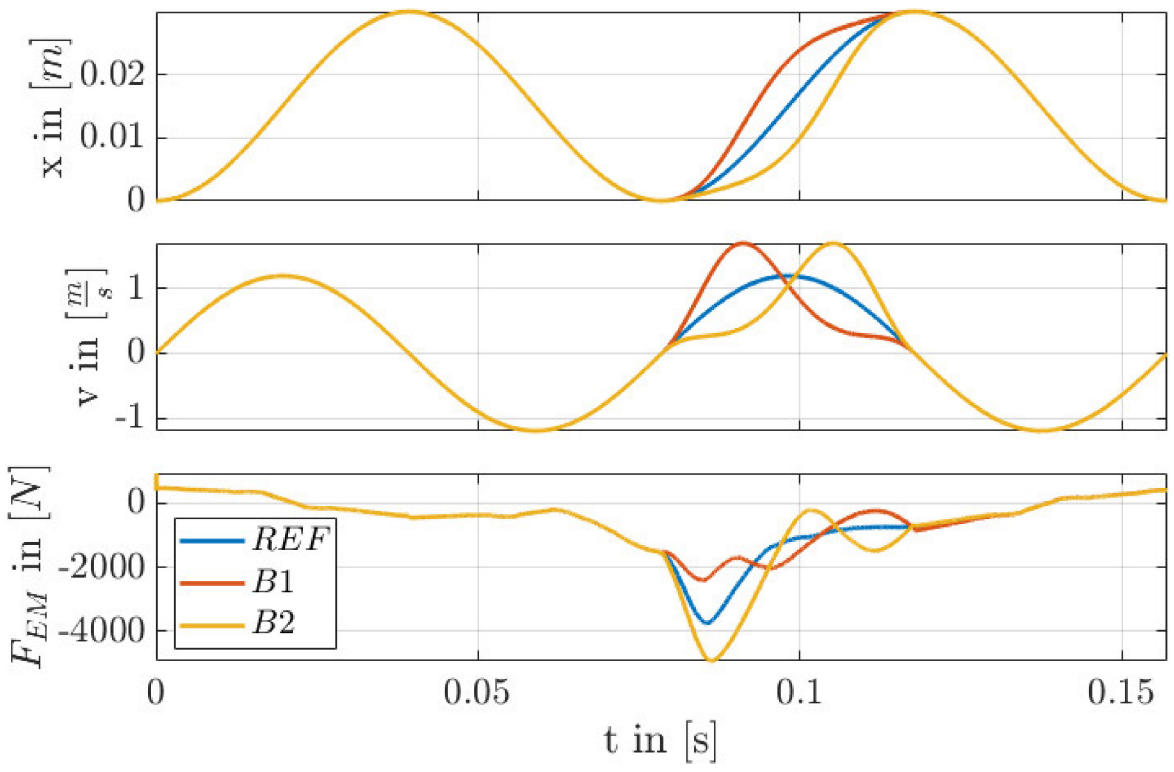

Figure 22. Comparison of trajectories REF, B1 and B2 related to the energy conversion of the electrical machine: illustration of the stroke, velocity and electric machine force depending on time. 


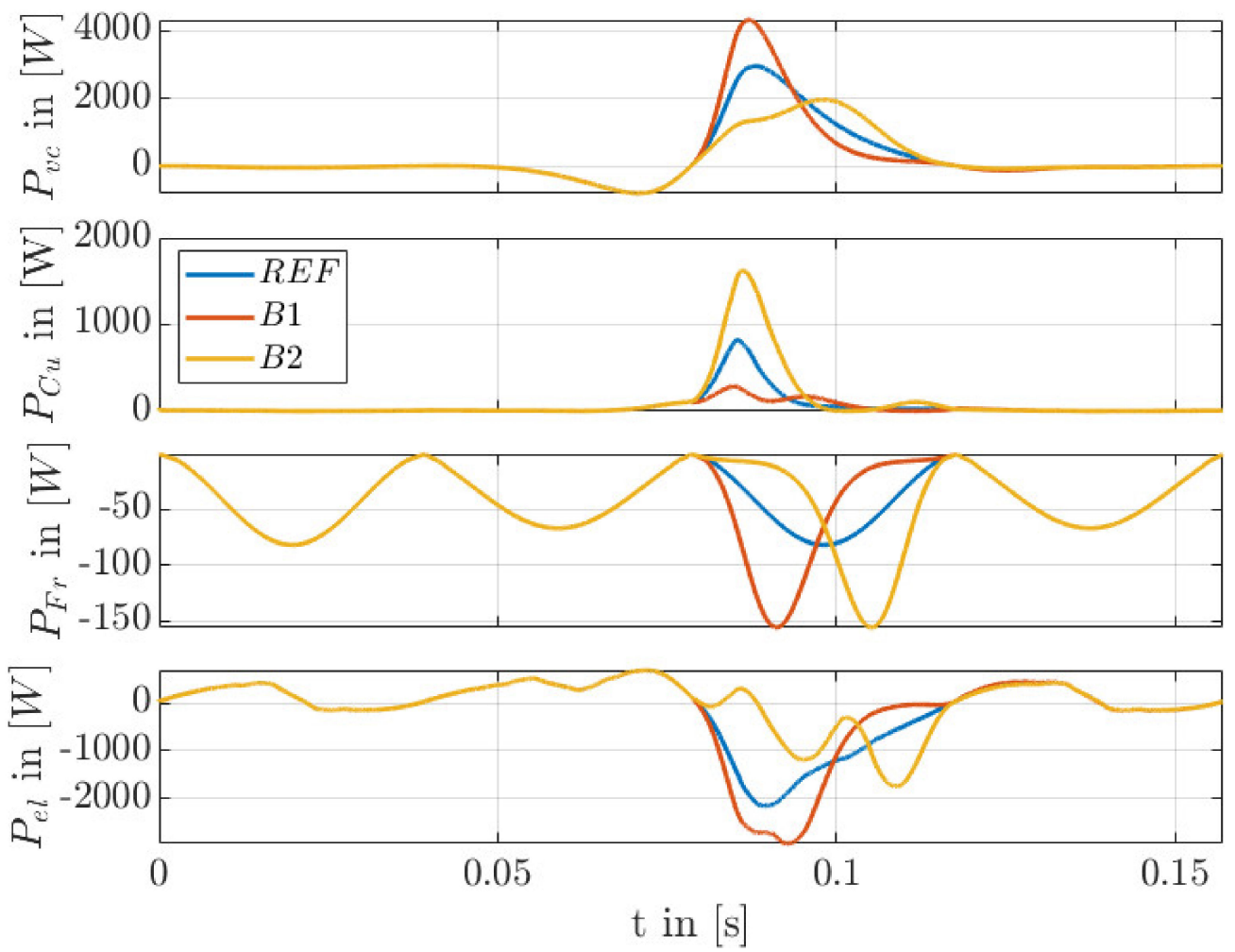

Figure 23. Comparison of trajectories REF, B1 and B2 related to the energy conversion of the electrical machine: volume change power, copper power losses, friction power losses and electric power depending on time.

Due to the slow change in the piston stroke in the trajectory B2, the electric machine must compensate for the force of the internal combustion engine so that a slow movement is possible. In contrast, in the case of trajectory B1, the piston is accelerated almost freely. As a result, the copper losses are high in case B2 and low in case B1. The friction losses are also approximately the same because the speed curve of B1 and B2 can be mirrored. Because of the reduced copper losses in case B1, the electrical energy conversion is good.

The loss analysis for B1 and B2 with respect to the reference is shown in Figure 24. Due to the fact that the maximum pressure has a strong influence on the fluid properties, and therefore, on the HTC, the wall heat losses for B1 are lower and for B2 higher in comparison to the reference. For the exhaust losses, this behavior is the other way around. Due to the higher temperature course for B1, especially when the exhaust valve opens, the exhaust losses increase in comparison to the reference. For B2, the temperature is lower when the exhaust valve opens. This leads to lower exhaust losses.

Figure 25 shows the courses for the piston motion, the pressure and temperature. The $\mathrm{PV}$ diagram for variant $\mathrm{C} 1$ and $\mathrm{C} 2$ in comparison to the reference is shown in Figure 26. The extended maximum stroke leads to no significant variance in the pressure and temperature courses. However, based on the different acceleration of the piston from TDCF to BDC, because of the different maximum strokes, which has to be reached in the same time, the PV diagram shows an extension of the included area to the end of the expansion stroke as well as a small decrease of the peak pressure. 


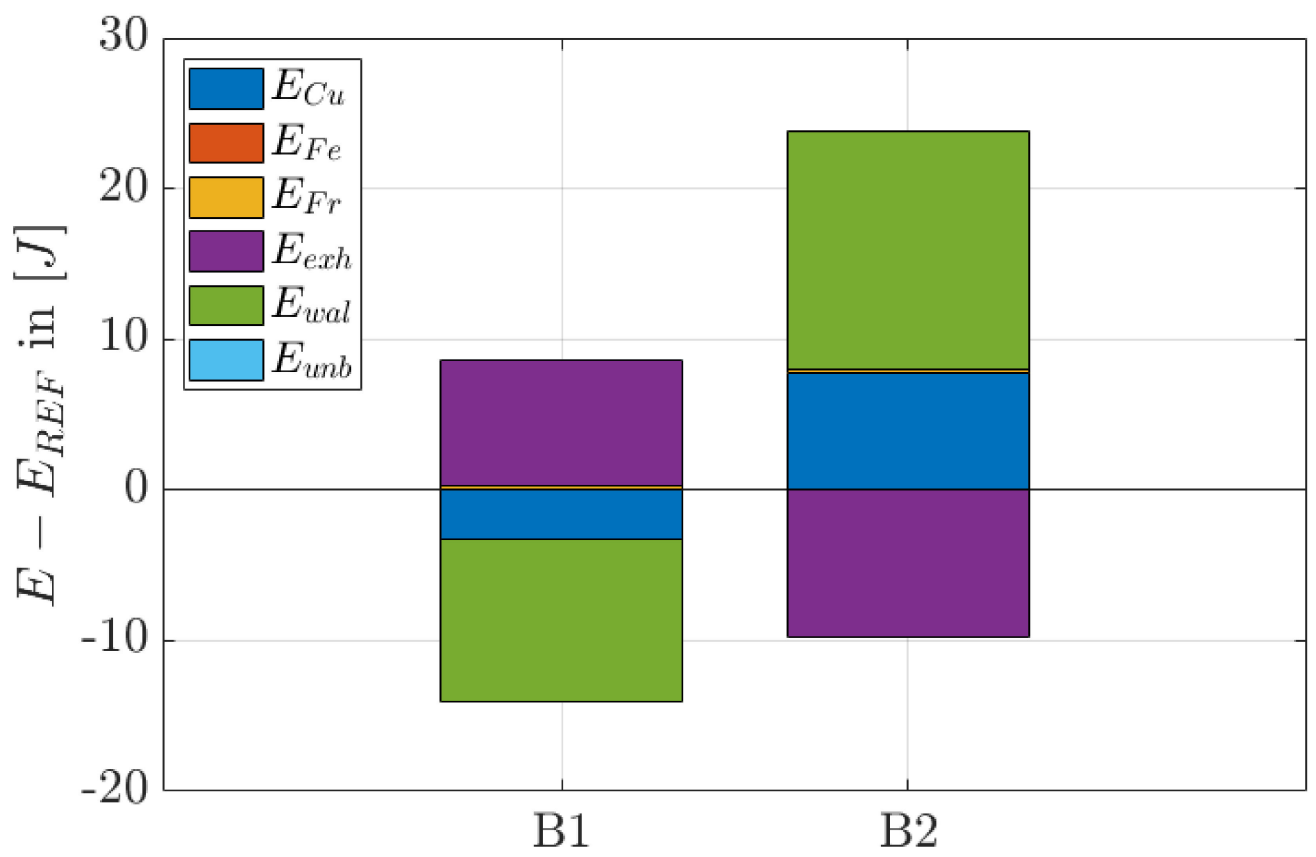

Figure 24. Energy losses for trajectory B1 and B2 with respect to REF.
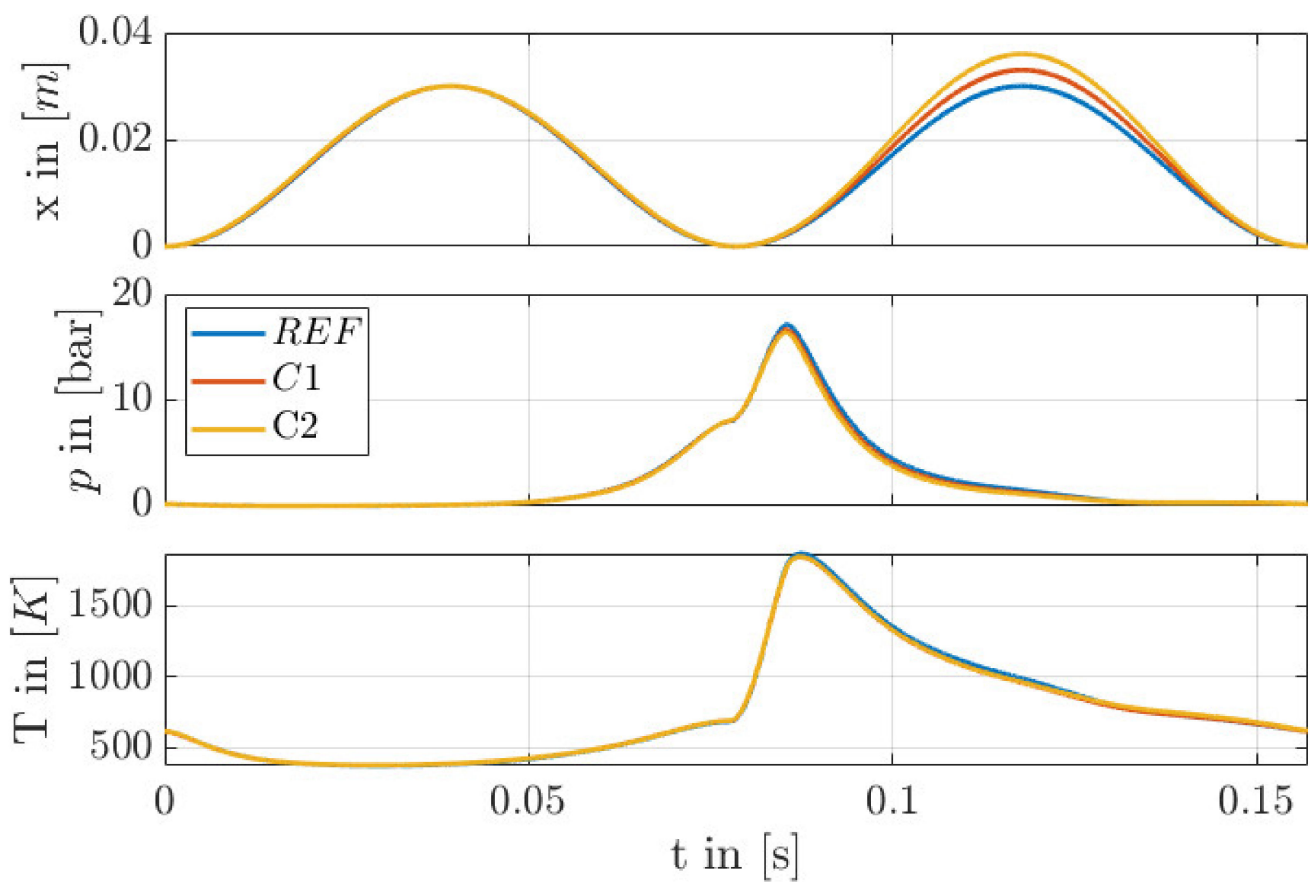

Figure 25. Comparison of trajectories REF, $\mathrm{C} 1$ and $\mathrm{C} 2$ related to the energy conversion of the internal combustion engine: illustration of the stroke, cylinder pressure and temperature depending on time. 


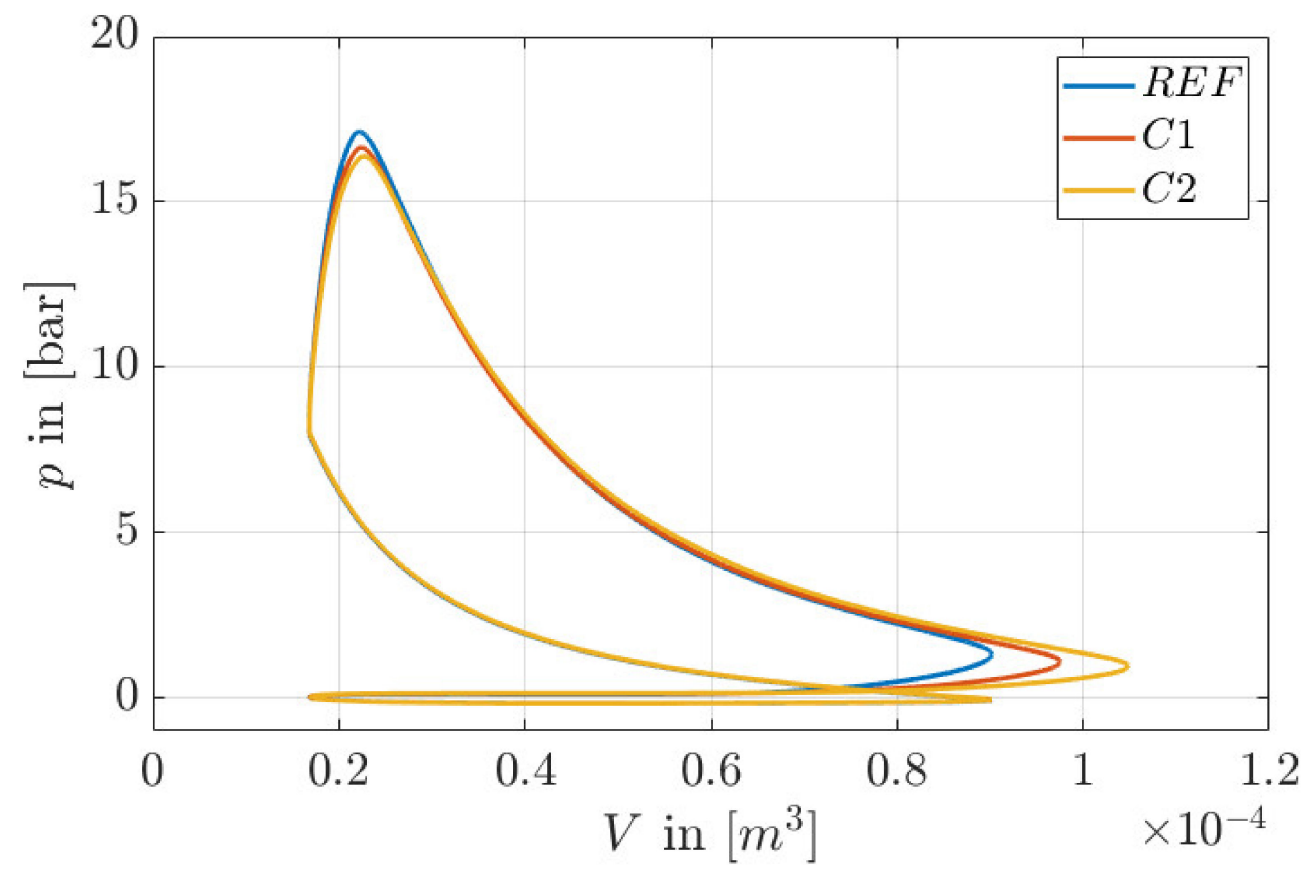

Figure 26. Comparison of trajectories REF, $\mathrm{C} 1$ and $\mathrm{C} 2$ related to the energy conversion of the internal combustion engine: cylinder pressure depending on volume.

For the evaluation of the electrical energy conversion of the trajectory REF, C1, C2, the stroke, speed and force of the electrical machine are shown in Figure 27 and the volume change, copper, friction and electrical power are shown in Figure 28.
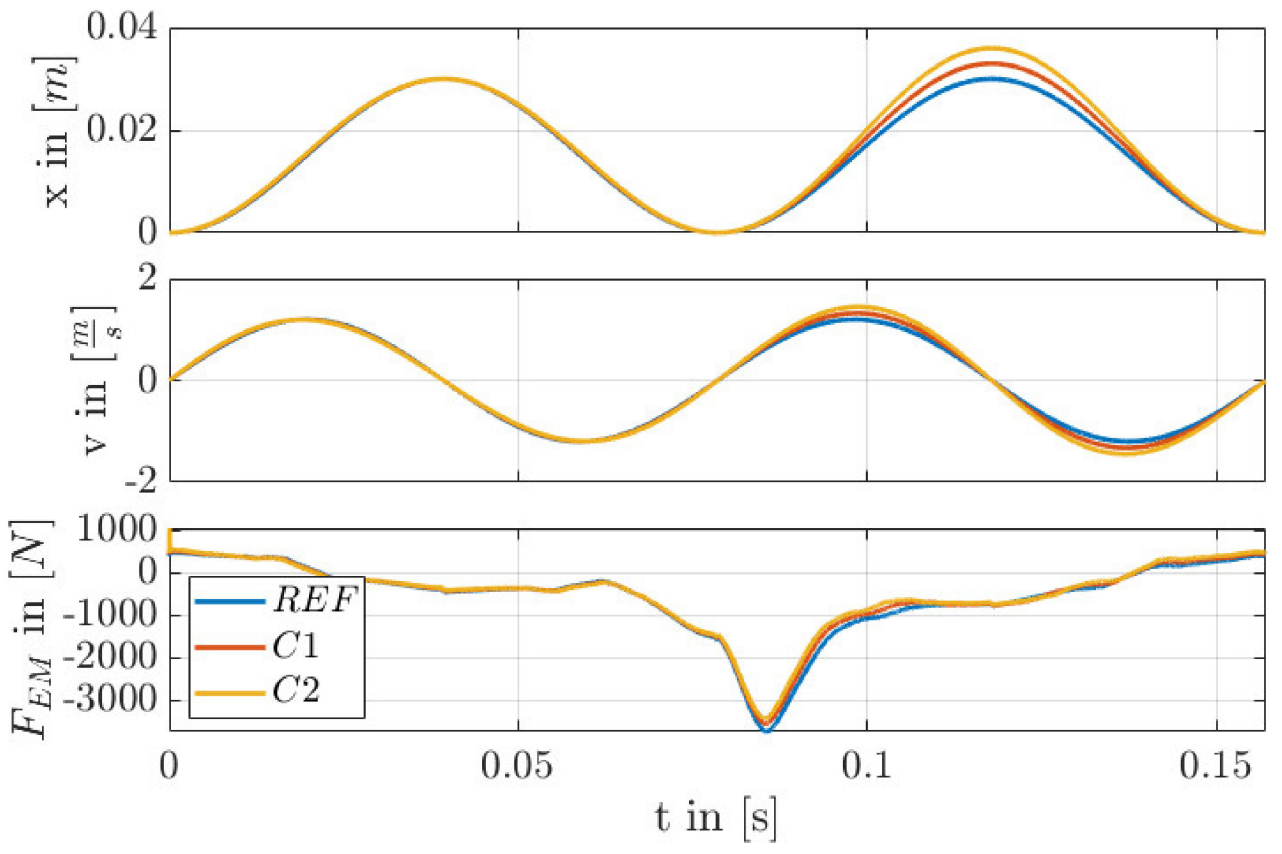

Figure 27. Comparison of trajectories REF, $\mathrm{C} 1$ and $\mathrm{C} 2$ related to the energy conversion of the electrical machine: illustration of the stroke, velocity and electric machine force depending on time. 


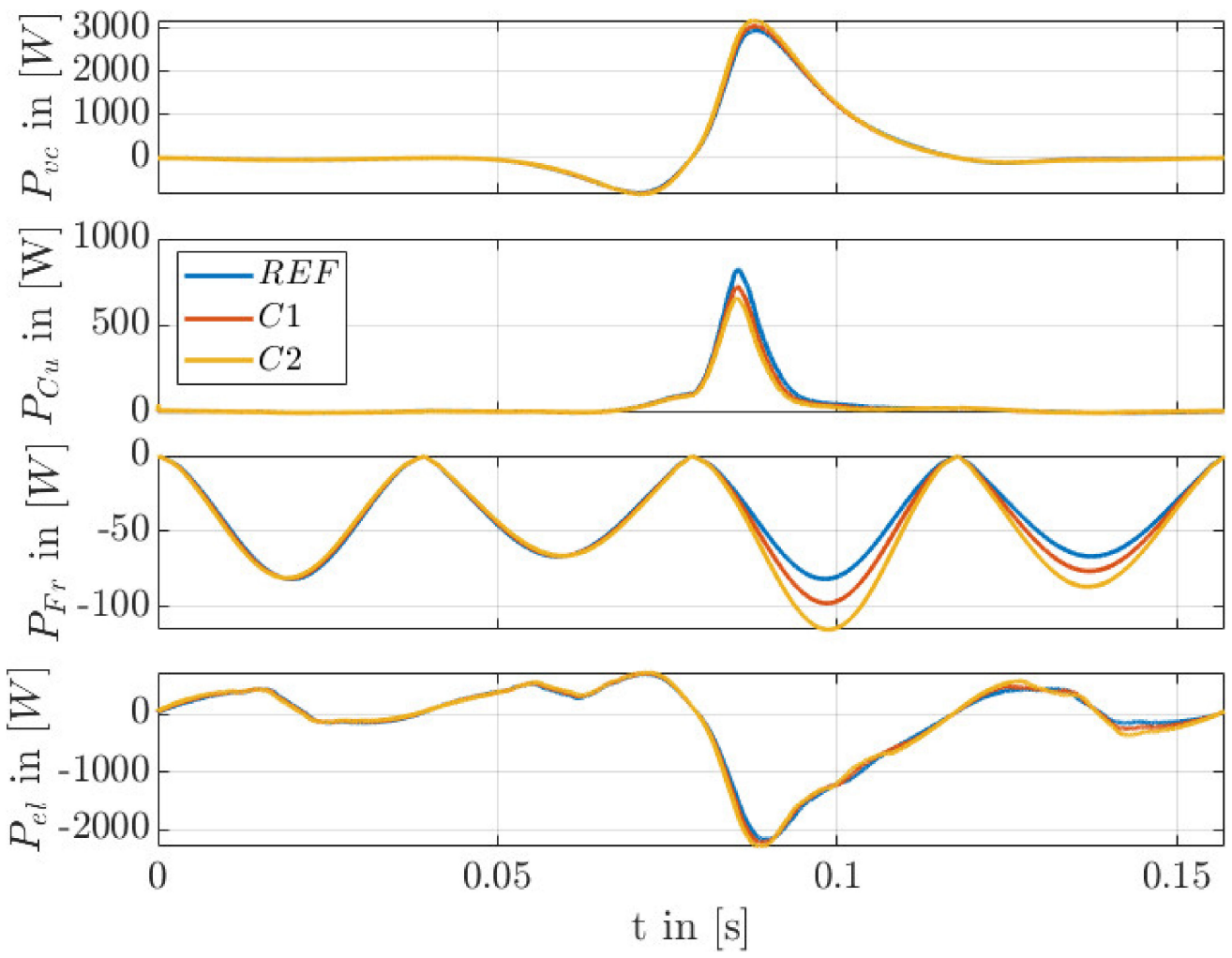

Figure 28. Comparison of trajectories REF, $\mathrm{C} 1$ and $\mathrm{C} 2$ related to the energy conversion of the electrical machine: volume change power, copper power losses, friction power losses and electric power depending on time.

Due to the stroke amplitude variation, the required speed increases in the expansion and exhaust cycle. The increase in speed leads to higher friction losses. However, the required acceleration in the expansion stroke is also increased. Since the combustion engine releases energy in this cycle, the electric machine does not have to brake the piston as hard. An increase in the stroke amplitude at this operating point has resulted in the copper losses being reduced. The iron losses have also increased, as the stroke variation leads to an increase in the electrical frequency.

The higher acceleration of the piston from TDCF to BDC leads to a small decrease of the peak pressure, which has a positive (reducing) influence on the wall heat losses. Against that, the higher maximum stroke leads to a higher surface area of the combustion chamber. This has a negative (increasing) influence on the wall heat losses. For the variant $\mathrm{C} 1$, the second phenomenon has a greater influence. This changes for the variant C2; thus, the first phenomenon has a greater influence. Therefore, the wall heat losses for $\mathrm{C} 1$ are higher and the wall heat losses for $\mathrm{C} 2$ are lower in comparison to the reference shown in Figure 29. The exhaust losses for $\mathrm{C} 1$ and $\mathrm{C} 2$ are lower than the exhaust losses from the reference. With higher maximum stroke, the benefit from the reduced exhaust losses decreases.

Figure 30 shows the courses for the piston motion, pressure and temperature. The PV diagram for variant D1 and D2 in comparison to the reference is shown in Figure 31. Because of the combination of moving the TDCF to an earlier point in time and the increased acceleration of the piston during the expansion near the TDCF, the courses of D1 and D2 are the superimposition of the variation of $\mathrm{A}$ and $\mathrm{B} 1$. This leads to an earlier increase of the pressure similar to the TDCF shift to an earlier time. Contemporaneous with the peak pressure, decreases similar to the increased piston acceleration in comparison to the reference. The temperature course is parallel shifted similar to the TDCF shift to earlier. However, the decrease of the temperature during the expansion is slower for the increased piston acceleration. This leads to higher temperatures when the exhaust valve opens. 


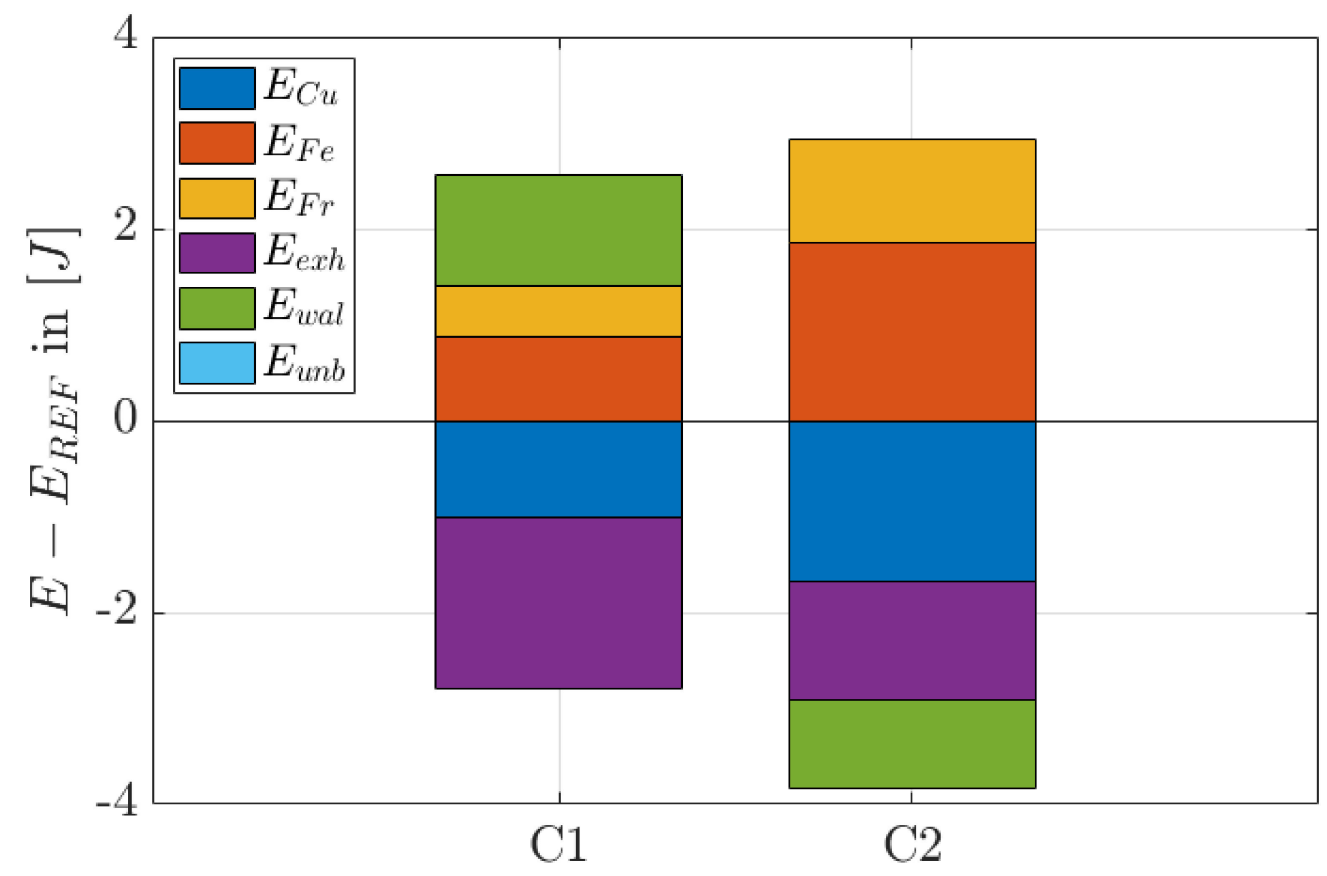

Figure 29. Energy losses for trajectory $\mathrm{C} 1$ and $\mathrm{C} 2$ with respect to REF.
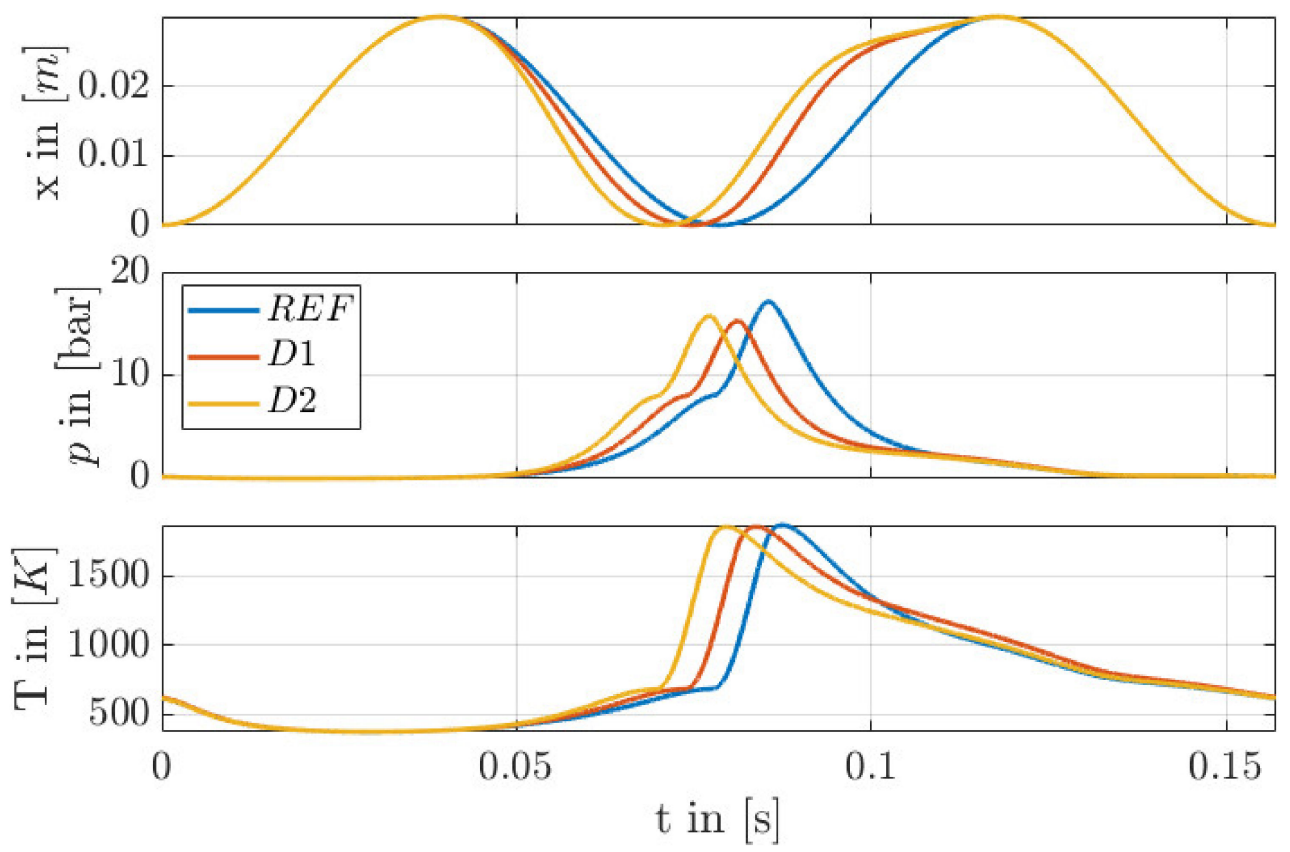

Figure 30. Comparison of trajectories REF, D1 and D2 related to the energy conversion of the internal combustion engine: illustration of the stroke, cylinder pressure and temperature depending on time. 


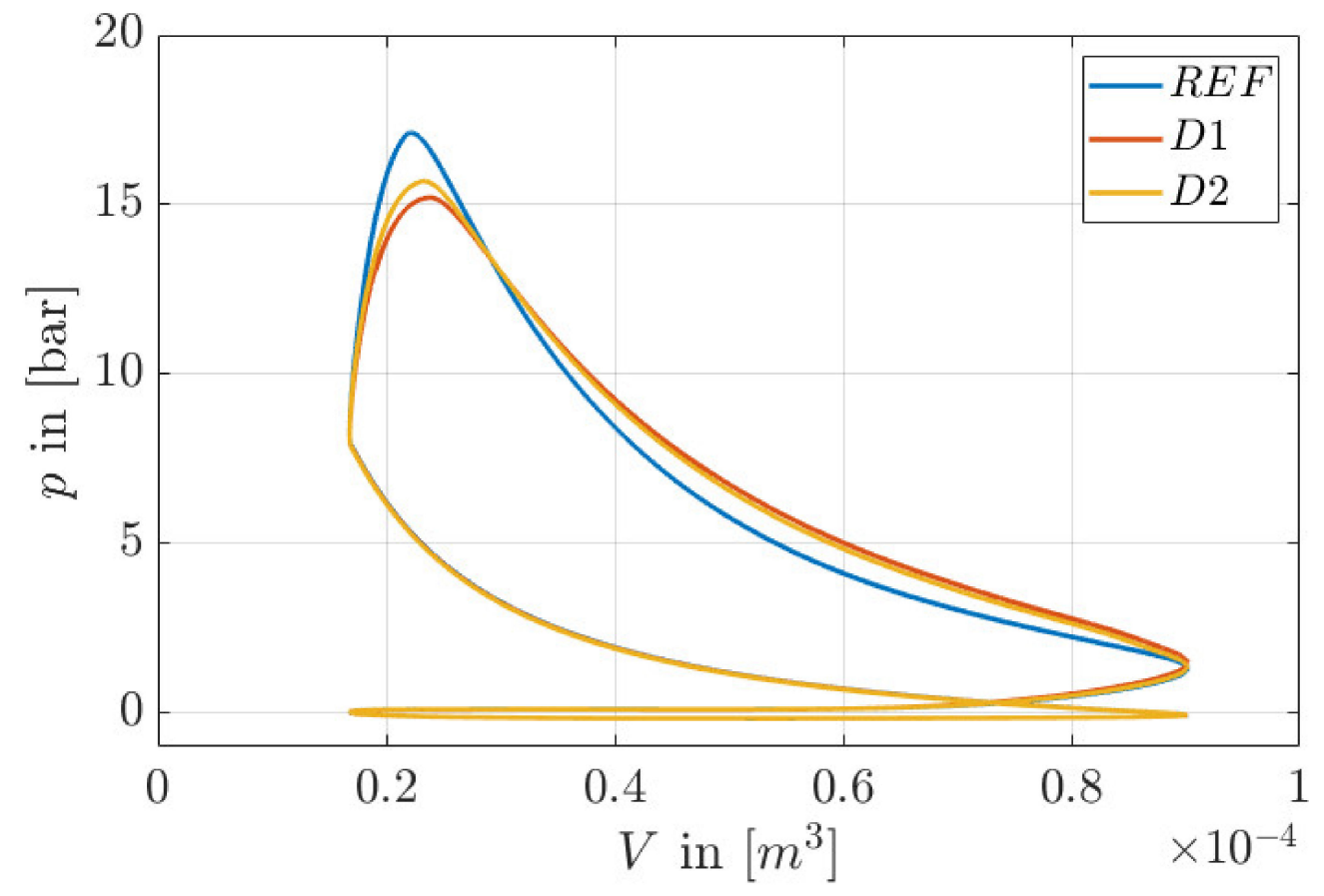

Figure 31. Comparison of trajectories REF, D1 and D2 related to the energy conversion of the internal combustion engine: cylinder pressure depending on volume.

For the evaluation of the electrical energy conversion of the trajectory REF, D1, D2, the stroke, speed and force of the electrical machine are shown in Figure 32 and the volume change, copper, friction and electrical power are shown in Figure 33.
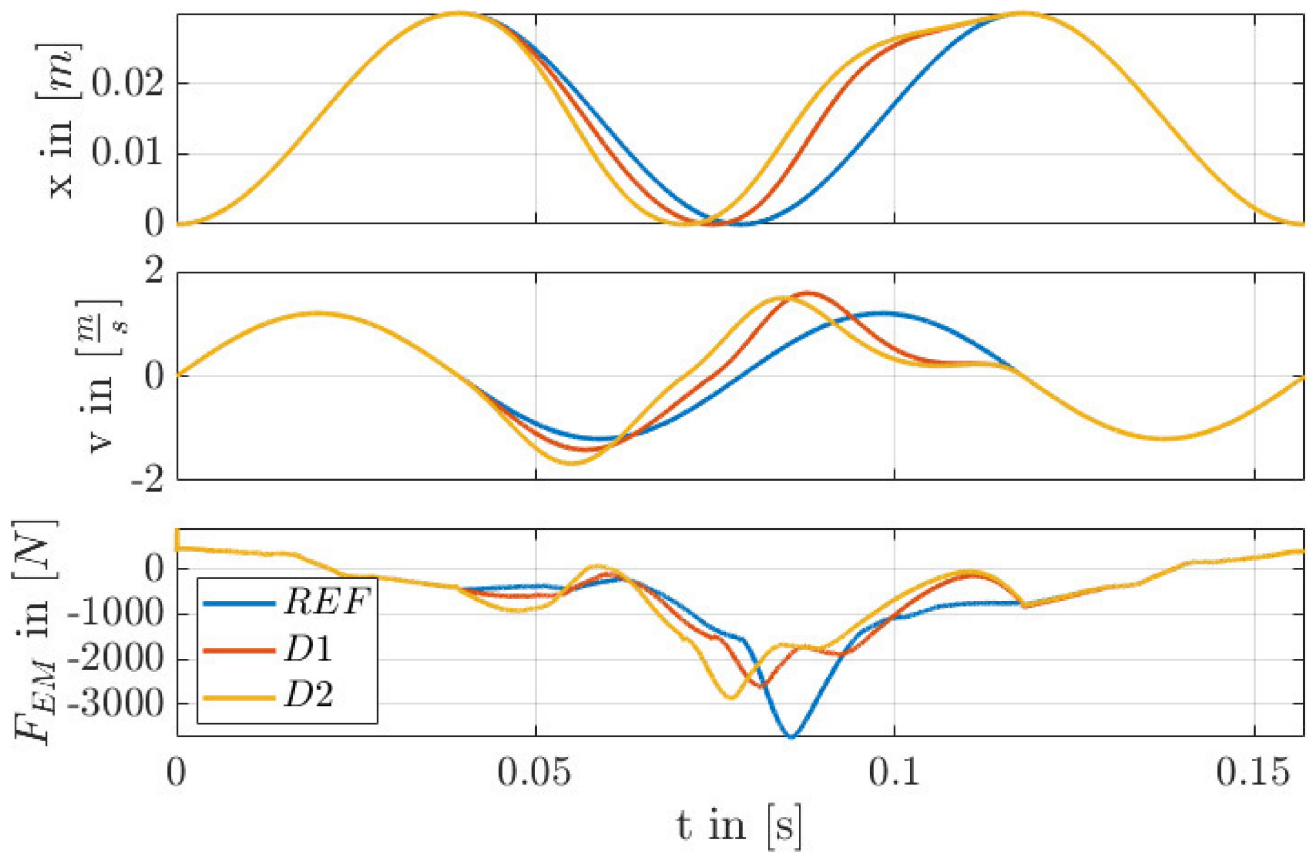

Figure 32. Comparison of trajectories REF, D1 and D2 related to the energy conversion of the electrical machine: illustration of the stroke, velocity and electric machine force depending on time. 


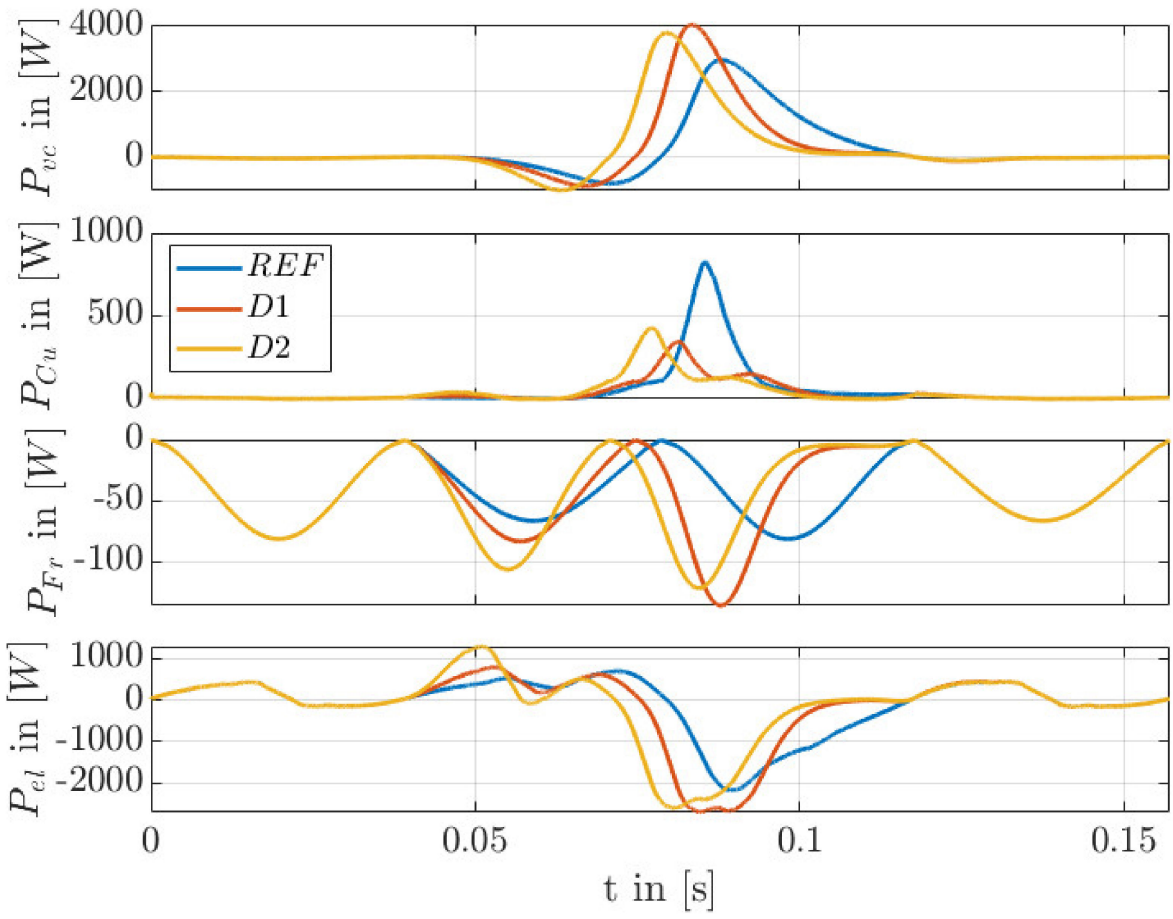

Figure 33. Comparison of trajectories REF, D1 and D2 related to the energy conversion of the electrical machine: volume change power, copper power losses, friction power losses and electric power depending on time.

The combination of variants A and B1 shows that the electrical machine must provide an adapted force curve. In this case, the copper losses in D1 are smaller than in D2, but the friction losses have increased.

The associated loss analysis for D1 and D2 with respect to the reference is shown in Figure 34. Due to the higher temperature when the exhaust valve opens, D1 has higher exhaust losses than D2, which has higher exhaust losses than the reference. Because of the lower pressure, D1 and D2 have lower wall heat losses than the reference. D1 has the lowest peak pressure. Therefore, the decrease of the wall heat losses for D1 is higher than for D2.

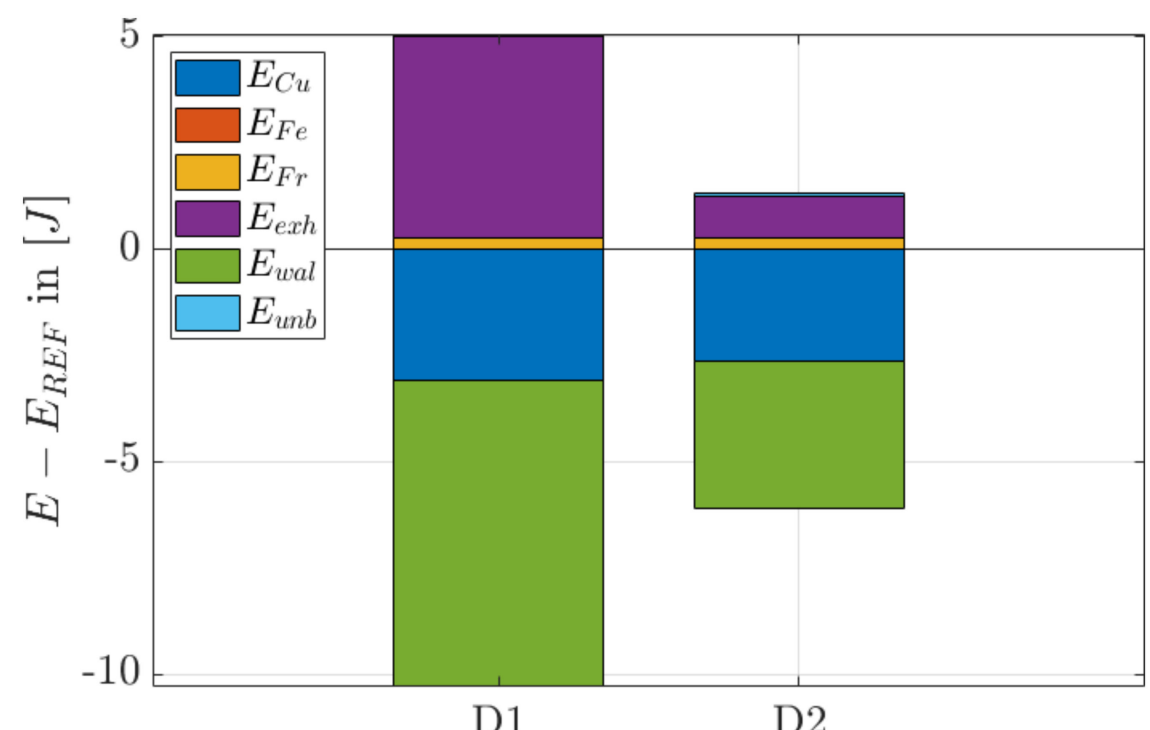

Figure 34. Energy losses for trajectory D1 and D2 with respect to REF. 
Figure 35 shows the electrical energy for all variants in comparison to the reference. The shifting of the TDCF to an earlier point in time shows a decrease of the effective efficiency. The lower exhaust losses are compensated by the increasing wall heat and copper losses. The increased piston acceleration shows the best results and the decreased acceleration the worst results. The decreased wall heat and copper losses are way higher than the increased exhaust losses for B1. This is the other way around for B2. The maximum piston stroke extension shows higher efficiency with increasing maximum piston stroke. This is based on the stronger decreasing wall heat losses in comparison to the increasing exhaust losses. The combination from A and B1 (D1 and D2) shows a decreasing efficiency with a higher shift of the TDCF identical to A. Due to the higher acceleration, the efficiency is on a higher level comparable to B1.

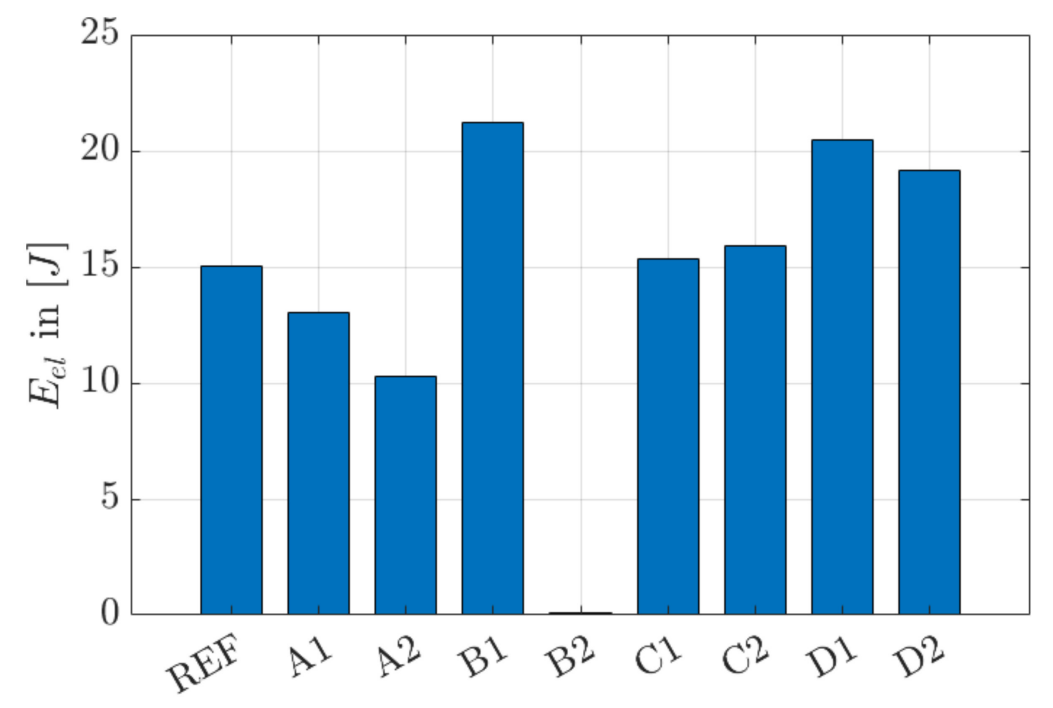

Figure 35. Comparison of the electrical energy conversion for the different trajectories.

Variant B1 shows the highest effective efficiency. The efficiency for the conversion from chemical energy within the fuel to electrical energy could be increased by $41 \%$.

\section{Conclusions}

The use of a harmonic sinus function for the piston motion leads to an imperfect conversion from chemical energy into electrical energy by using a free-piston engine. The optimization of the energy conversion is a complex challenge, because of several influences by the thermodynamic and electrical conversion. The results of the trajectory variation described in Section 7 have shown that an increased acceleration of the piston from TDCF to BDC leads to a strong decrease of the peak pressure, which results in a strong decrease of the wall heat losses. The analyzed trajectory B1 could show an increase of the efficiency by $41 \%$ for the energy conversion. In addition to the efficiency increase, it is possible to increase the inlet pressure to reach the same peak pressure as the reference. This would lead to an increased power density of the free-piston engine. Despite the optimization, the absolute electrical energy share is still low for the test engine. This is based on the fact that the test engine is very small and has a low thermal efficiency. Therefore, the results of this investigation have to be verified for bigger engines. Due to differing surface-to-volume ratios, it is possible that another trajectory shows better results than B1. The further steps for the free-piston engine investigations are the described verification for engines with higher bore diameter as well as an automated trajectory optimization. When optimizing the geometric parameters of the internal combustion engine, it must be considered that this leads to different requirements for the electrical machine. Combustion engines and electrical machines should, therefore, be optimally designed for each other. 
Author Contributions: Conceptualization, R.T. and A.G.; methodology, K.K.; software, R.T. and A.G.; validation, R.T. and A.G.; formal analysis, K.K.; investigation, R.T., A.G. and K.K.; resources, A.G. and S.B.; data curation, R.T. and A.G.; writing-original draft preparation, R.T., K.K. and A.G.; writing-review and editing, S.B., R.L. and H.R.; visualization, R.T. and A.G.; supervision, H.R. and R.L.; project administration, R.T. and A.G.; funding acquisition, R.T. All authors have read and agreed to the published version of the manuscript.

Funding: This research received no external funding.

Institutional Review Board Statement: Not applicable.

Informed Consent Statement: Not applicable.

Data Availability Statement: The data presented in this study are available on request from the corresponding author. The authors would like to know who re-uses their research materials and research data, which is why they would only share them on personal request.

Conflicts of Interest: The authors declare no conflict of interest.

\section{Nomenclature and Abbreviations}

\begin{tabular}{|c|c|c|c|}
\hline LHV & Lower heat value & $E_{i}$ & Energy [J] \\
\hline HTC & Heat transfer coefficient & $m_{i}$ & Mass $[\mathrm{kg}]$ \\
\hline PC & Personal computer & $\eta_{i}$ & Efficiency [-] \\
\hline PMSM & $\begin{array}{l}\text { Permanent magnet excited } \\
\text { synchronous machine }\end{array}$ & $A_{i}$ & Area $\left[m^{2}\right]$ \\
\hline IMEP & Indicated mean effective pressure & $T$ & Temperature $[\mathrm{K}]$ \\
\hline SI-Turb & $\begin{array}{l}\text { Spark-Ignition Turbulent Flame } \\
\text { Model }\end{array}$ & $T_{\text {in }}$ & Inlet temperature $[\mathrm{K}]$ \\
\hline TDCF & Top dead center firing & & \\
\hline REF & Reference case & $T_{\text {out }}$ & Outlet temperature $[\mathrm{K}]$ \\
\hline A1 & Low TDC shift & $t$ & Time $[\mathrm{s}]$ \\
\hline $\mathrm{A} 2$ & High TDC shift & $\alpha$ & Heat transfer coefficient $\left[\mathrm{W} /\left(\mathrm{m}^{2} \mathrm{~K}\right)\right]$ \\
\hline B1 & Early piston acceleration & $c_{p}$ & Mean specific heat capacity $[\mathrm{J} /(\mathrm{kg} \mathrm{K})]$ \\
\hline B2 & Late piston acceleration & $P$ & Power $[\mathrm{W}]$ \\
\hline $\mathrm{C} 1$ & Low stroke amplitude change & $v$ & Velocity $[\mathrm{m} / \mathrm{s}]$ \\
\hline $\mathrm{C} 2$ & High stroke amplitude change & $F$ & Force $[\mathrm{N}]$ \\
\hline D1 & $\begin{array}{l}\text { Combination of early piston } \\
\text { acceleration and low TDC shift }\end{array}$ & $\mu$ & Friction coefficient [-] \\
\hline D2 & $\begin{array}{l}\text { Combination of early piston } \\
\text { acceleration and high TDC shift }\end{array}$ & $p$ & Cylinder pressure $[\mathrm{Pa}]$ \\
\hline$x$ & Stroke $[\mathrm{m}]$ & $i_{i}$ & Current $[\mathrm{A}]$ \\
\hline$T_{i}$ & Duration of the cycle $[\mathrm{s}]$ & $\omega$ & Virtual angular velocity \\
\hline$\Delta T_{i}$ & Relative duration change [-] & $\varphi$ & Virtual angle \\
\hline$k_{F}$ & Force constant $[\mathrm{N} / \mathrm{A}]$ & $f$ & Frequency $[\mathrm{Hz}]$ \\
\hline$R$ & Ohmic resistance $[\Omega]$ & $B$ & Magnetic flux density [T] \\
\hline$u_{i}$ & Voltage [V] & $\phi$ & Equivalence ratio [-] \\
\hline$\rho_{u}$ & Unburned density $\left[\mathrm{kg} / \mathrm{m}^{3}\right]$ & $a$ & Acceleration $\left[\mathrm{m} / \mathrm{s}^{2}\right]$ \\
\hline$S_{T}$ & Turbulent flame speed [m/s] & $S_{L}$ & Laminar flame speed $[\mathrm{m} / \mathrm{s}]$ \\
\hline$C_{T F S}$ & $\begin{array}{l}\text { Turbulent flame speed multiplier } \\
{[-]}\end{array}$ & $C_{F K G}$ & Flame kernel growth multiplier [-] \\
\hline$R_{f}$ & Flame radius $[\mathrm{m}]$ & $L_{i}$ & Integral length scale [-] \\
\hline$B_{m}$ & Maximum laminar speed [m/s] & $B_{\phi}$ & Laminar speed roll-off value $[\mathrm{m} / \mathrm{s}]$ \\
\hline$\phi_{m}$ & $\begin{array}{l}\text { Equivalence ratio at maximum } \\
\text { speed }[\mathrm{m} / \mathrm{s}]\end{array}$ & $T_{u}$ & Unburned gas temperature $[\mathrm{K}]$ \\
\hline$\alpha_{e}$ & Temperature exponent [-] & $\beta$ & Pressure exponent [-] \\
\hline$w$ & $\begin{array}{l}\text { Average cylinder gas velocity } \\
{[\mathrm{m} / \mathrm{s}]}\end{array}$ & $K_{i}$ & Model constant [-] \\
\hline
\end{tabular}




\section{References}

1. Rahman, S.M.A.; Rizwanul Fattah, I.M.; Ong, H.C.; Zamri, M.F.M.A. State-of-the-Art of Strategies to Reduce Exhaust Emissions from Diesel Engine Vehicles. Energies 2021, 14, 1766. [CrossRef]

2. Burnete, N.V.; Mariasiu, F.; Moldovanu, D.; Depcik, C. Simulink Model of a Thermoelectric Generator for Vehicle Waste Heat Recovery. Appl. Sci. 2021, 11, 1340. [CrossRef]

3. Woo, S.; Lee, J.; Han, Y.; Yoon, Y. Experimental Study of the Combustion Efficiency in Multi-Element Gas-Centered Swirl Coaxial Injectors. Energies 2020, 13, 6055. [CrossRef]

4. Chen, P.-T.; Yang, C.-J.; Huang, K.D. Dynamic Simulation and Control of a New Parallel Hybrid Power System. Appl. Sci. 2020, 10, 5467. [CrossRef]

5. Gerlach, A.; Fritsch, M.; Benecke, S.; Rottengruber, H.; Leidhold, R. Variable Valve Timing With Only One Camshaft Actuator for a Single-Cylinder Engine. IEEE/ASME Trans. Mechatron. 2019, 24, 1839-1850. [CrossRef]

6. Wrobel, R.; Sierzputowski, G.; Sroka, Z.; Dimitrov, R. Comparison of Diesel Engine Vibroacoustic Properties Powered by Bio and Standard Fuel. Energies 2021, 14, 1478. [CrossRef]

7. Sato, M.; Goto, T.; Zheng, J.; Irie, S. Resonant Combustion Start Considering Potential Energy of Free-Piston Engine Generator. Energies 2020, 13, 5754. [CrossRef]

8. Zhang, Z.; Feng, H.; Zuo, Z. Numerical Investigation of a Free-Piston Hydrogen-Gasoline Engine Linear Generator. Energies 2020, 13, 4685. [CrossRef]

9. Zhang, Q.; Xu, Z.; Liu, S.; Liu, L. Effects of Injector Spray Angle on Performance of an Opposed-Piston Free-Piston Engine. Energies 2020, 13, 3735. [CrossRef]

10. Hu, Y.; Xu, Z.; Sun, Y.; Liu, L. Electromagnetic Characteristics Analysis of a Tubular Moving Magnet Linear Generator System. Appl. Sci. 2020, 10, 3713. [CrossRef]

11. Hu, Y.; Xu, Z.; Yang, L.; Liu, L. Electromagnetic Loss Analysis of a Linear Motor System Designed for a Free-Piston Engine Generator. Electronics 2020, 9, 621. [CrossRef]

12. Graef, M.; Treffinger, P.; Pohl, S.-E.; Rinderknecht, F. Investigation of a high efficient Free Piston Linear Generator with variable Stroke and variable Compression Ratio A new Approach for Free Piston Engines. World Electr. Veh. J. 2007, 1, 116-120. [CrossRef]

13. Kock, F.; Haag, J.; Friedrich, H.E. The Free Piston Linear Generator-Development of an Innovative, Compact, Highly Efficient Range-Extender Module. In SAE 2013 World Congress E Exhibition, APR. 16; SAE International400 Commonwealth Drive: Warrendale, PA, USA, 2013.

14. Kosaka, H.; Akita, T.; Moriya, K.; Goto, S.; Hotta, Y.; Umeno, T.; Nakakita, K. Development of Free Piston Engine Linear Generator System Part 1-Investigation of Fundamental Characteristics. In SAE 2014 World Congress E Exhibition, APR. 08; SAE International400 Commonwealth Drive: Warrendale, PA, USA, 2014.

15. Virsik, R.; Heron, A. Free piston linear generator in comparison to other range-extender technologies. World Electr. Veh. J. 2013, 6, 426-432. [CrossRef]

16. Zhang, C.; Chen, F.; Li, L.; Xu, Z.; Liu, L.; Yang, G.; Lian, H.; Tian, Y. A Free-Piston Linear Generator Control Strategy for Improving Output Power. Energies 2018, 11, 135. [CrossRef]

17. Gerlach, A.; Rottengruber, H.; Leidhold, R. Control of a Directly Driven Four-Stroke Free Piston Engine. In Proceedings of the IECON 2018-44th Annual Conference of the IEEE Industrial Electronics Society, Washington, DC, USA, 21-23 October 2018; pp. 4525-4530, ISBN 978-1-5090-6684-1.

18. Li, K.; Zhang, C.; Sun, Z. Precise piston trajectory control for a free piston engine. Control Eng. Pract. 2015, 34, 30-38. [CrossRef]

19. Vu, D.N.; Lim, O. Piston motion control for a dual free piston linear generator: Predictive-fuzzy logic control approach. J. Mech. Sci. Technol. 2020, 34, 4785-4795. [CrossRef]

20. Bashir, A.; Zulkifli, S.A.; Abidin, E.Z.Z.; Aziz, A.R.A. Control of Piston Trajectory in a Free-Piston Linear Electric Generator by Load Current Modulation. In Proceedings of the 2020 IEEE Student Conference on Research and Development (SCOReD), Batu Pahat, Malaysia, 27-29 September 2020; pp. 465-470, ISBN 978-1-7281-9317-5.

21. Zhang, C.; Li, K.; Sun, Z. Modeling of piston trajectory-based HCCI combustion enabled by a free piston engine. Appl. Energy 2015, 139, 313-326. [CrossRef]

22. Kim, J.; Bae, C.; Kim, G. Simulation on the effect of the combustion parameters on the piston dynamics and engine performance using the Wiebe function in a free piston engine. Appl. Energy 2013, 107, 446-455. [CrossRef]

23. Feng, H.; Guo, C.; Yuan, C.; Guo, Y.; Zuo, Z.; Roskilly, A.P.; Jia, B. Research on combustion process of a free piston diesel linear generator. Appl. Energy 2016, 161, 395-403. [CrossRef]

24. Yuan, C.; Feng, H.; He, Y.; Xu, J. Combustion characteristics analysis of a free-piston engine generator coupling with dynamic and scavenging. Energy 2016, 102, 637-649. [CrossRef]

25. Chiang, C.-J.; Yang, J.-L.; Lan, S.-Y.; Shei, T.-W.; Chiang, W.-S.; Chen, B.-L. Dynamic modeling of a SI/HCCI free-piston engine generator with electric mechanical valves. Appl. Energy 2013, 102, 336-346. [CrossRef]

26. Jia, B.; Smallbone, A.; Feng, H.; Tian, G.; Zuo, Z.; Roskilly, A.P. A fast response free-piston engine generator numerical model for control applications. Appl. Energy 2016, 162, 321-329. [CrossRef]

27. Arshad, W.M.; Thelin, P.; Backstrom, T.; Sadarangani, C. Use of Transverse-Flux Machines in a Free-Piston Generator. IEEE Trans. Ind. Applicat. 2004, 40, 1092-1100. [CrossRef] 
28. Xu, Z.; Chang, S. Improved Moving Coil Electric Machine for Internal Combustion Linear Generator. IEEE Trans. Energy Convers. 2010, 25, 281-286. [CrossRef]

29. Benecke, S.; Gerlach, A.; Leidhold, R. Design Principle for Linear Electrical Machines to Minimize Power Loss in Periodic Motions. IEEE Trans. Ind. Applicat. 2020, 56, 4820-4828. [CrossRef]

30. Zhang, C.; Sun, Z. Trajectory-based combustion control for renewable fuels in free piston engines. Appl. Energy 2017, 187, 72-83. [CrossRef]

31. Xu, J.; Yuan, C.; He, Y.; Wang, R. An optimization of free-piston engine generator combustion using variable piston motion. Adv. Mech. Eng. 2017, 9, 168781401772087. [CrossRef]

32. Tipler, P.A.; Mosca, G. Physics for Scientists and Engineers: With Modern Physics, 6th ed.; Extended Version; Chapter 1-41; Freeman: New York, NY, USA, 2008; ISBN 1429202653.

33. Rinderknecht, F. A highly efficient energy converter for a hybrid vehicle concept-focused on the linear generator of the next generation. In Proceedings of the 8th International Conference and Exhibition on Ecological Vehicles and Renewable Energies (EVER), Grimaldi Forum, Monte Carlo, Monaco, 27-30 March 2013; IEEE: Piscataway, NJ, USA, 2013; ISBN 9781467352710.

34. Li, Q.-F.; Xiao, J.; Huang, Z. Flat-type permanent magnet linear alternator: A suitable device for a free piston linear alternator. J. Zhejiang Univ. Sci. A 2009, 10, 345-352. [CrossRef]

35. Zhang, B. Modellierung und Hocheffiziente Berechnung der Lastabhängigen Eisenverluste in Permanentmagneterregten Synchronmaschinen; KIT Scientific Publishing: Karlsruhe, Germany, 2019.

36. Rhodes, D.B.; Keck, J.C. Laminar Burning Speed Measurements of Indolene-Air-Diluent Mixtures at High Pressures and Temperatures. In SAE International Congress and Exposition, FEB. 25; SAE International: Warrendale, PA, USA, 1985.

37. Gamma Technologies LLC. GT-SUITE-Engine Performance-Application Manual; Gamma Technologies LLC: Westmont, IL, USA, 2019. 